\title{
Cranial phenotypic variation in Meriones crassus and M. libycus (Rodentia, Gerbillinae), and a morphological divergence in M. crassus from the Iranian Plateau and Mesopotamia (Western Zagros Mountains)
}

\author{
Fatemeh TABATABAEI YAZDI ${ }^{1}$, Dominique ADRIAENS ${ }^{2}$ \& Jamshid DARVISH ${ }^{3}$ \\ ${ }^{1}$ Faculty of Natural resources and Environment, Ferdowsi University of Mashhad, Azadi Square, \\ 91735 Mashhad, Iran \\ Email: f.tabatabaei@um.ac.ir; fatemeh.tabata@gmail.com (corresponding author) \\ ${ }^{2}$ Ghent University, Evolutionary Morphology of Vertebrates, K.L. Ledeganckstraat 35, \\ 9000 Gent, Belgium \\ ${ }^{3}$ Rodentology Research Department and Institute of Applied Zoology, Ferdowsi University of Mashhad, \\ Azadi Square, 91735 Mashhad, Iran \\ ${ }^{1}$ urn:lsid:zoobank.org:author:0E8C5199-1642-448A-80BB-C342C2DB65E9 \\ ${ }^{2}$ urn:lsid:zoobank.org:author:38C489B9-2059-4633-8E3D-C531FE3EDD8B \\ ${ }^{3}$ urn:lsid:zoobank.org:author:9F7A70C9-C460-495A-9258-57CB5E7E9DFA
}

\begin{abstract}
Jirds (genus Meriones) are a diverse group of rodents, with a wide distribution range in Iran. Sundevall's jird (Meriones crassus Sundevall, 1842) is one such species that shows a disjunct distribution, found on the Iranian Plateau and Western Zagros Mountains. Morphological differences observed between these two populations, however, lack quantitative support. Morphological differences between geographical populations of Meriones crassus were analysed and compared with those of the sympatric M. libycus. Similarities in the cranial morphology of these species were found, e.g. in a relatively large and inflated bulla. A two-dimensional geometric morphometric analysis was done on the skull of 275 M. crassus and $220 \mathrm{M}$. libycus from more than 70 different localities in their distribution range. Results confirm cranial differences between specimens of M. crassus from the Western Zagros and those from Africa and Arabia, mainly at the level of the relative size of the tympanic bulla, that were significantly correlated with the annual rainfall and elevation. Moreover, the study supports the hypothesis that the Western Zagros specimens are both a geographically and phenotypically distinct group compared to the other Iranian M. crassus specimens, suggesting that the former might be a distinct species.
\end{abstract}

Key words. geometric morphometrics, morphology, Middle East, Muridae, skull shape.

Tabatabaei Yazdi F., Adriaens D. \& Darvish J. 2014. Cranial phenotypic variation in Meriones crassus and M. libycus (Rodentia, Gerbillinae), and a morphological divergence in M. crassus from the Iranian Plateau and Mesopotamia (Western Zagros Mountains). European Journal of Taxonomy 88: 1-28. http://dx.doi.org/10.5852/ejt.2014.88

\section{Introduction}

Jirds, belonging to the genus Meriones Illiger, 1811 (Rodentia, Gerbillinae), are a diverse group of murid rodents that are distributed from North Africa to China, with 17 recognized species. The Sundevall's 
jird (Meriones crassus Sundevall, 1842) and Libyan jird (M. libycus Lichtenstein, 1823) are known to show both similarities in their morphological features and their distribution, with the Middle East and the Iranian Plateau being a biogeographically important part of their distribution range (Misonne 1959, 1975; Firouz 2005). In addition, Iran and the Iranian Plateau are of considerable zoogeographical interest within the Palearctic region because of their great biodiversity (Anderson 1989).

Across their distribution range, Sundevall's jirds live in diverse habitats and geoclimatic conditions. Intraspecific variation among geographic populations of $M$. crassus (having formed the basis for the recognition of numerous subspecies) could actually reflect morphological plasticity in relation to environmental conditions. As such, this study deals with geoclimatic correlations of skull variation within this species, in order to test whether this relationship can be quantified. Also, since the level of interspecific morphological differences in jirds is poorly understood, M. crassus is compared with its closest congener, M. libycus.

Identification keys to M. crassus and M. libycus are mostly based on hind-claw colour, the auditory bulla and the suprameatal triangle condition (Sénégas 2001; Pavlinov 2008), with their respective subspecies generally not sharply defined and with similar appearances within the two species. Several keys and reviews provide some diagnostic features for these species, but most of them, e.g. for Libya (Ranck 1968), Egypt (Osborn \& Helmy 1980), Arabia (Harrison 1972) and Iran (Lay 1967), are regional in scope.

Meriones crassus is cranially distinguishable from M. libycus by a less robust cranium and a more inflated mastoid chamber and tympanic bulla. Nevertheless, some of the M. libycus subspecies, such as M. l. arimalius Cheesman and Hinton, 1924, have been distinguished by their larger tympanic bullae, so being similar to that of $M$. crassus (Ellerman 1948). On the other hand, subspecies of $M$. crassus, such as the poorly known M. c. longifrons Lataste, 1884 and M. c. charon Thomas, 1919, were defined by their less swollen bulla (Thomas 1919; Chaworth-Musters \& Ellerman 1947; Ellerman 1948; Wittmer and Büttiker 1982). The natural boundaries between these and other subspecies of $M$. crassus are very poorly known, partly due to diagnostic features often being based on a few specimens. For M. c. longifrons, diagnostic features were even based on specimens kept in captivity and on specimens collected in the vicinity of just a single city (Harrison 1972).

Moreover, the impact of geoclimatic conditions on inter- and intraspecific morphological differences has been suggested in the past, e.g. in the studies by Petter (1961), Pavlinov \& Rogovin (2000), Sénégas (2001), Chevret \& Dobigny (2005), Darvish (2009) and Tabatabaei Yazdi \& Adriaens (2011). The relationship between environmental variation, especially aridity, and morphological variation in jirds - mainly on the hypertrophy of the bulla - has long been recognized (Misonne 1959; Harrison 1972; Musser \& Carleton 2005; Darvish 2009; Tabatabaei Yazdi \& Adriaens 2011; Tabatabaei Yazdi et al. 2012). Thus, the existence of environmental correlations with the cranial morphology in the studied jirds can be expected. A limited number of studies that included traditionally measured body and skull size in some jird species have already mentioned the existence of a correlation between the shape variation (i.e. hypertrophy of bulla) and aridity in jirds (Pavlinov \& Rogovin 2000; Chevret \& Dobigny 2005; Momenzadeh et al. 2008; Darvish 2009). However, the degree to which climate and morphological variations in jird species can be correlated has never been quantified. Hence, this study deals with the correlation between cranial shape variation, proven to be essential for systematic and taxonomic studies in jirds (e.g. by Chaworth-Musters \& Ellerman 1947; Pavlinov 2008), and some climatic variables that are important limiting factors for the jirds' habitats (aridity and altitude).

Meriones crassus occurs across north Africa from Morocco to Egypt south to Sudan; also in Asia through the Arabian Peninsula north to Turkey and east to Afghanistan and western Pakistan (Musser \& Carleton 
2005). In Iran, M. crassus comprises two geographically disjunct populations (Misonne 1959; Lay 1967; Koffler 1972), one occurring in the central and eastern part of the Iranian Plateau and the other presently known from the lowlands of the Khuzestan Plain in the southwest of Iran. The Western Iran M. crassus specimens have been considered as a distinct subspecies (M. c. charon) in the literature (ChaworthMusters \& Ellerman 1947; Petter 1961), and hence some phenotypic differences can be expected considering the different environmental conditions associated with the habitat. Thus, the existence of an association between geoclimatological conditions and morphological variation in M. crassus is tested in this study, relying on a large sample representing the known distribution range of this species and using detailed descriptors of skull size and shape. To this end, we performed a landmark-based geometric morphometric analysis on the skulls of Meriones specimens diagnosed as M. crassus and originating from the localities known to span the distribution of the subspecies recognised within it, including type specimens and specimens originating from type localities.

More concretely, this study aimed to evaluate whether (1) specimens of M. crassus from the Western Zagros considered as M. crassus charon (Ellerman 1948; Harrison 1956; Hatt 1959) can be distinguished from those specimens distributed across the Iranian Plateau, as well as from M. crassus specimens that originated from other parts of the species' distribution range; (2) morphological differences between the Western Zagros M. crassus and a cluster containing the other $M$. crassus populations are at a similar level as that observed at the inter-specific level; (3) cranial variation in Sundevall and Libyan jirds reveals different patterns in relation to geoclimatic variation, and (4) the cranial differences are correlated with the geoclimatic variables.

\section{Material and methods}

\section{Abbreviations}

$\begin{array}{ll}\text { 2B-PLS } & =\text { two-block partial least square } \\ \text { CVA } & =\text { canonical variate analysis (CV plots) } \\ \text { M2 } & \text { second molar } \\ \text { MANOVA } & \text { multivariate analysis of variance } \\ \text { MANCOVA } & =\text { multivariate analysis of covariance } \\ \text { NJ } & =\text { neighbour joining } \\ \text { NPMANOVA } & =\text { non-parametric MANOVA } \\ \text { OTU } & =\text { operational taxonomic unit } \\ \text { PAST } & =\text { PAlaeontologica STatistics } \\ \text { PCA } & =\text { principal component analysis } \\ \text { RW } & =\text { relative warps } \\ \text { SPSS } & =\text { Statistical Package for the Social Sciences } \\ \text { UPGMA } & \text { unweighted pair-group average cluster analysis } \\ \text { BMNH } & =\text { British Museum of Natural History ( = Natural History Museum, London) } \\ \text { FAO } & =\text { United Nations Food And Agriculture Organization, Rome } \\ \text { FMNH } & =\text { Field Museum of Natural History, Chicago } \\ \text { MNHN } & =\text { Muséum national d'Histoire naturelle, Paris } \\ \text { USNM } & =\text { Smithsonian National Museum of Natural History, Washington D.C. }\end{array}$

\section{Specimens analysed}

For this study, a total of 495 skulls ( 275 for Meriones crassus and 220 for M. libycus) was used. Juvenile specimens, identified on the basis of the eruption and amount of wear on the molars (M2) (Petter 1959; Tong 1989; Pavlinov 2008), were excluded from the analyses. The studied specimens of M. crassus range from the Western Sahara to the Balochistan province of Pakistan, located at the southeastern edge of the 
Iranian Plateau, whereas the specimens of M. libycus have been collected from Algeria to Afghanistan (province of Kandahar). The specimens were obtained from the collections of the Smithsonian Museum of Natural History (Washington D.C., USA), the Field Museum of Natural History (Chicago, USA), the British Museum of Natural History (London, UK), the Muséum national d'Histoire naturelle (Paris, France), the Zoological Museum of Ferdowsi University of Mashhad (Mashhad, Iran) and the Royal Belgian Institute of Natural Sciences (Brussels, Belgium). A list of specimens, with catalogue numbers, is available in Appendix 1. The species names on the museum labels were included as metadata. However, specimens were re-identified based on all external and cranial data available, following the keys of Chaworth-Muster \& Ellerman (1947) and Osborn \& Helmy (1980). External characters could be verified on most specimens (as collection specimens included both skull and skin). In order to be able to re-assign the specimens to nominal taxa, the available type specimens (Table 1) in these collections were examined and included in the analyses. The samples of $M$. crassus for the analyses of the variation patterns were pooled into seven groups. In order to test shape differences, specimens were pooled into four groups (according to their geoclimatic proximity in habitat and geographical range), namely: Iranian Plateau, Western Zagros, Arabia and Africa, with 137, 48, 32 and 54 specimens, respectively. The specimens from Kuwait, Jordan and northwestern Saudi Arabia (NW Arabia) were included in the Arabic group. The Jeddah locality was excluded from CVA because of the low sample size (four specimens) and the inclusion of some captive-bred specimens.

The specimen sampling localities are listed in Appendix 2, their geographic coordinates were plotted with ArcGIS (http://www.esri.com), ArcMap 9.2 (Fig. 1).

\section{Morphological and geoclimatic data acquisition}

The use of landmark data to describe variation in both skull size and shape in mammals is well established for taxonomic and phenotypic evolutionary studies (Rohlf \& Marcus 1993; Fadda \& Corti 2001; Barciova \& Macholán 2006; Cardini et al. 2007; Macholán et al. 2008). Because studies amply indicated geometric morphometrics as a powerful tool for studying shape variation (e.g. Bookstein 1991; Rohlf \& Marcus 1993; Adams \& Rohlf 2000), this approach was followed in this study. As the skull phenotype is genetically and functionally more complex than teeth (Caumul and Polly 2005; CordeiroEstrela et al. 2008), it probably represents relevant biological variation of underlying natural groups.

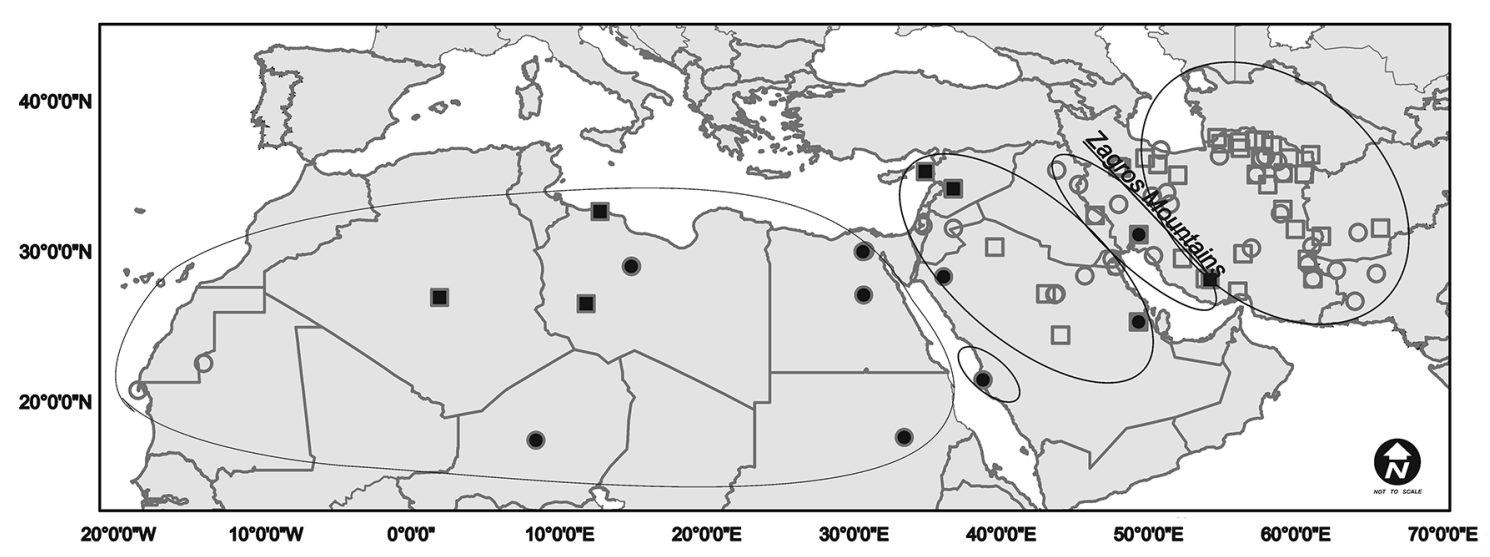

Fig. 1. Map showing the sampling localities of Meriones crassus Sundevall, 1842 (circles) and M. libycus Lichtenstein, 1823 (squares) and groups of sampling localities indicated by ellipses (see more detail about the grouping in Material and Methods). The dark closed symbols are the sampling localities of the type specimens (synonyms of Meriones crassus and M. libycus, see Table 1). The ellipses (from left to right) show the following groups: African, Jeddah, Arabian, Western Zagros and Iranian Plateau. 
TABATABAEI YAZDI F., ADRIAENS D. \& DARVISH J., Morphological variation in jirds

Table 1. List of type specimens included in this study. Synonyms are according to Musser \& Carleton (2005).

\begin{tabular}{|l|l|c|c|}
\hline \multicolumn{1}{|c|}{ Taxon } & Synonym & Type locality & Collection \\
\hline M. caudatus amplus & M. libycus & Libya, Fezzan, Gatrun & USNM \\
\hline M. caudatus luridus & M. libycus & Libya, Cyrenaica, Bahr El Tubat, 21 km E of Bahr El Tubat & USNM \\
\hline M. crassus asyutensis & M. crassus & Egypt, Asyut, 13 mil SE of Asyut & FMNH \\
\hline M. crassus charon & M. crassus & Iran, Khuzestan, Ahwaz & BMNH \\
\hline M. crassus ismahelis & M. crassus & Arabia, Hufuf & BMNH \\
\hline M. crassus longifrons & M. crassus & Arabia, Jedda & BMNH \\
\hline M. crassus pallidus & M. crassus & Sudan, Atbara & BMNH \\
\hline M. crassus pelerinus & M. crassus & Arabia, Tebuk & BMNH \\
\hline M. crassus perpallidus & M. crassus & Egypt, Wadi Gedeed, Cairo, 4 km W of Cairo-Alexandria rd & FMNH \\
\hline M. crassus tripolidus & M. crassus & Libya, Gebel Limhersuk & BMNH \\
\hline M. crassus tuareg & M. crassus & Niger, Teguidda, near Tisem, west of Asben & BMNH \\
\hline M. erythrourus farsi & M. libycus & Iran, Fars, Bariz, 3 km N of Bariz, 50 km N of Lar & USNM \\
\hline M. libycus aquilo & M. libycus & China, Zungaria, Gutschen & BMNH \\
\hline M. libycus caudatus & M. libycus & Libya, Tripolitania, Bir Ferdjan & BMNH \\
\hline M. libycus gaetulus & M. libycus & Algeria & BMNH \\
\hline M. libycus schouesboeii & M. libycus & Algeria, Tieret, Tibremt & BMNH \\
\hline M. syrius & M. libycus & Syria, Al Qariatayn, Syrian Desert & BMNH \\
\hline M. syrius edithae & M. libycus & Arabia, Hufuf, Khudud Spring & BMNH \\
\hline M. syrius evelynae & & Arabia, Hufuf, Khorassan Spring & BMNH \\
\hline
\end{tabular}

Landmark data in two-dimensional planes were collected from photographs taken with a Nikon D70 digital reflex camera using a Sigma $105 \mathrm{~mm}$ macro lens at five megapixels in a standardized manner. The camera was placed on a tripod parallel to the ground plane. The intact and cleaned skulls were mounted in a box with glass pearls. Left-right symmetry on the ventral and dorsal sides, and a perfect overlap at the level of bullae, teeth rows and the optic canals on the lateral side, were the most important criteria to position the skulls in a standardized way. The ventral, dorsal and lateral sides of the skulls were photographed. In each photograph, a scale was included by adding a piece of millimeter paper. This allowed the acquisition of a scaling factor for calculating centroid sizes (an overall size measure based on landmark coordinates). Landmark configurations representing the three sides of the skulls were digitized using the software TpsDig 2.12 (Rohlf 2004a). To avoid digitisation of both sides of asymmetrical skulls (hence generating a substantial increase in the number of shape variables), we tested for left-right differences on the dorsal and ventral faces of the skulls in a subsample of 20 specimens of each species of the dataset. A Monte Carlo randomization (based on partial warp scores, see below) showed that skulls were symmetrical ( $\mathrm{p} \geq 0.726)$. As such, only one side (left) of the skulls was further digitised and included in the analyses. This first test revealed, that digitised coordinates of one side could be reliably mirrored to the other side along the midline in case of broken skulls (Elewa 2004), which could thus still be included in this study. On the ventral, dorsal and lateral sides of the cranium, respectively 20,19 and 22 landmarks were chosen on the condition that they include all relevant structures which may be expected to reflect the morphological variation (Fig. 2). In order to efficiently capture the shape and size of the tympanic bulla, three additional landmarks were digitized (Fig. 2, open circles). The landmark positions are defined in Appendix 3, based on the terminology used by Popesko et al. (2002) and Tong (1989). Doing the analyses without the semi-landmarks (that could be correlated to other landmarks and hence could influence the results) revealed no significant differences. Hence, all the landmarks were included to represent a reference of the mediosagittal plane. 
For the analyses, data from different skull views were considered to encompass all variation patterns exhibited by structural components that are not visible in all the views (Monteiro et al. 2003).

Geoclimatic data were taken from published records of the Iranian Meteorological Organization and the FAO climate database (FAO 2007): latitude, longitude, elevation $(\mathrm{m})$, temperature $\left({ }^{\circ} \mathrm{C}\right)$ (mean annual, monthly maximum and monthly minimum), and annual rainfall ( $\mathrm{mm}$ ). For sampling localities for which no specific climatic data was available (e.g. small villages), the geoclimatic data of the closest city were used. The average annual rainfall data for each sampling locality was calculated based on data over a period of ten years (1995-2005).

\section{Data analysis}

\section{Shape analysis}

In order to standardise the data, a Generalised Procrustes Analysis was performed (non-shape differences were removed), using TpsRelw 1.46 (Rohlf 1999, 2008) and PAST (PAlaeontologica STatistics) ver. 1.74 (Hammer et al. 2001). As such, landmark configurations were aligned by Procrustes superimposition and were scaled to unit centroid size (to remove morphological variation due to size, rotation and translation) (Gower 1975; Bookstein et al. 1985; Rohlf \& Slice 1990; Rohlf 1995, 1999; Rohlf \& Marcus 1993). Relying on the thin plate spline approach (see Rohlf 1995; Zelditch et al. 2004), variation in shape coordinates was decomposed in partial warps (shape variables explaining shape variation at different scales within the landmark configurations), thus generating a matrix of partial warp scores for each of the specimens. For this analysis, both uniform and non-uniform partial warps were included to span the full spectrum of shape variation, thus yielding the so-called weight matrix (Rohlf \& Bookstein 2003). This matrix was then used for further multivariate statistical analyses. A classifier analysis was done in PAST on the combination of the partial warp scores of the dorsal, ventral and lateral sides of the specimens. We tested how well specimens were assigned to the a priori taxa. Since the shape variation at different levels of local scale were given equal weight (alpha $=1)$, the PCA (see below) corresponds to a principal component analysis on Procrustes coordinates. But, just as in a PCA, the principal axes explain different percentages of the total amount of variation, where these principal components are then referred to as 'relative warps' (RW) (Rohlf 1993).

Principal component analysis (PCA), using PAST, and Canonical variate analysis (CVA), using STATISTICA (StatSoft, ver. 7.0), were performed on partial warp scores of each data set separately for the dorsal, ventral and lateral view to investigate the intraspecific variation and morphological differences among the OTUs. The scatter plots, illustrating the results of PCA and CVA analyses, were generated in STATISTICA to visualize how specimen groups are distributed in morphospace. Visualization of shape changes by deformation grids was generated using TpsSplin 1.20 (Rohlf 2004b). For the PC plots (Figs 3,6), deformation grids represent shape difference between configurations corresponding to lowest and highest RW-values. For the CV plots (Figs 4, 7), these grids visualize the shape differences when following the trajectory within the morphospace along the arrows and between the groups' consensuses (calculated using TpsSmall 1.20) (Rohlf 2003). To further test reliability of the outcome of the canonical variate analyses, a classifier analysis was done on the pooled partial warp scores of the dorsal, ventral and lateral views. To test for shape differences among the groups, the basic assumptions for doing a parametric test were not met. Hence, partial warp scores of the defined groups were subjected to a nonparametric MANOVA(NPMANOVA in PAST with 10000 permutations, bonferroni-corrected p-values). The pairwise testing for shape differences between all compared groups was done with a Monte Carlo randomization (10000 permutations, bonferroni-corrected p-values) on Euclidean distances between group means using the Poptools 3.2.3 plug-in (Hood 2010) for Microsoft Office Excel 2007. This test was done both for each side of the skull (ventral, dorsal and lateral) separately, as well as for the pooled dataset of the M. crassus groups. However, as this yielded a very high number of shape variables (110 in 
total), the number of informative variables was reduced by using PCA-scores of this dataset of those PCs that explained $95 \%$ of the shape variation. In that way, the number of variables could be reduced to 50 .

In order to compare to what degree geographical affinities reflected shape similarities between the M. crassus groups and to evaluate the overall morphological similarities between them, a neighbour joining (NJ clustering) and unweighted pair-group average cluster analysis (UPGMA), were performed on the matrix of shape distances (Euclidean Distances) between the group means (using PAST). For the latter analyses, the partial warp scores for the three views (ventral, dorsal and lateral) were pooled to calculate the group average. Since the Euclidean distance is a robust and widely applicable measure for testing morphological similarities (Raup \& Crick 1979) and the procrustes distances were highly correlated to the tangent distances, the corresponding matrix of Euclidean distances (calculated using Poptools 3.2.3) was used for the pairwise testing. The robustness of the resulting clustering trees (branch supports) was estimated by performing a bootstrapping of 10000 randomizations using PAST.

To test to what degree the observed shape differences between the $M$. crassus groups were explained by size-independent differences, a MANCOVA was performed on the RW-scores (explaining more than

A

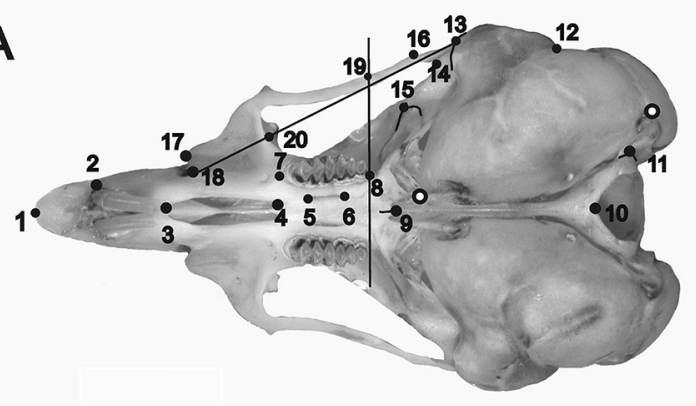

B

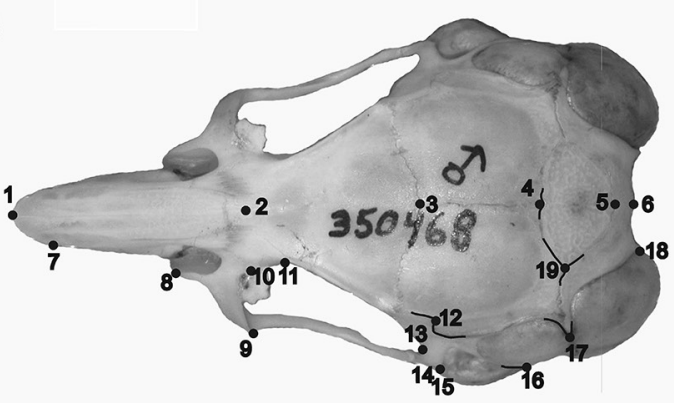

C

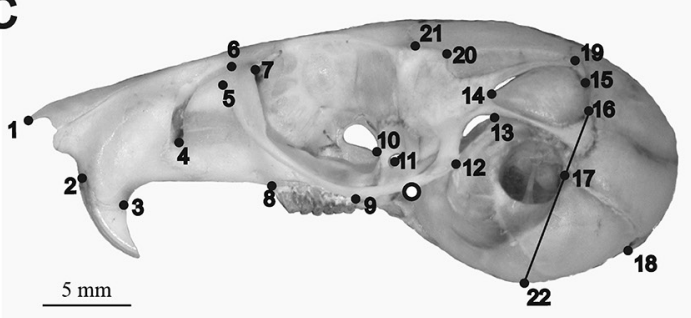

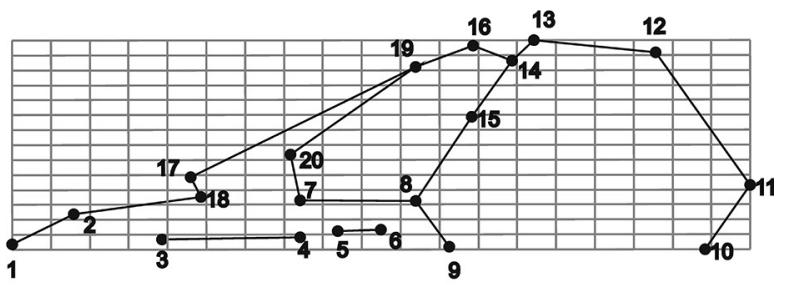
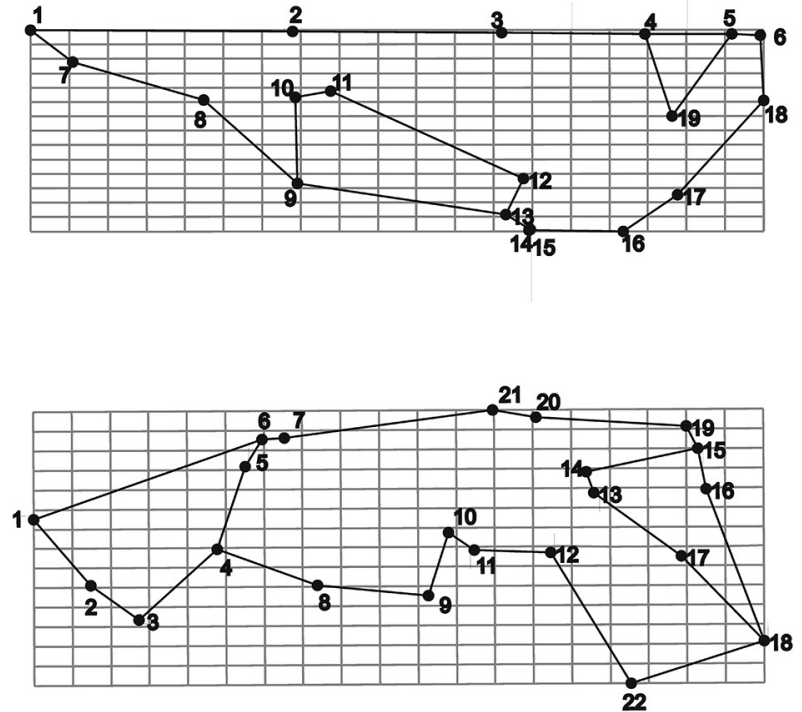

Fig. 2. Landmarks positioned on the cranium of Meriones crassus Sundevall, 1842 shown in (A) ventral (B) dorsal and (C) lateral views. The straight lines on the ventral and lateral views were used for defining semi-landmarks based on two other landmarks. Open circles on the ventral side: the most rostral and on the most caudal point of the tympanic bulla, and on the lateral side: the most rostral margin of the tympanic bulla. Short lines are drawn to highlight sutures which are unclear here and on which the landmarks have been defined. 
$95 \%$ of shape variations) of ventral shape variables, with centroid size as the co-variate and M. crassus groups as the fixed factor, using SPSS (Statistical Package for the Social Sciences ver. 15.0).

A factorial MANCOVA was performed on the same shape variables (explaining more than $95 \%$ of shape variations) using SPSS, with centroid size as the co-variate and M. crassus groups and sex (sex per OTU interaction in MANCOVA) as the fixed factors to test for sexual dimorphism as well.

A two-block partial least square (2B-PLS) analysis (Rohlf \& Corti 2000) was used to analyse the covariation between the overall skull shape and geoclimatic variables. The 2B-PLS constructs pairs of vectors, representing linear combinations of the variables within each data set, in such a way that the vectors account for as much of the covariation between the two original sets of variables as possible. The new variables describe what patterns, if any, of covariation exist between the two sets of original variables (see Rohlf \& Corti 2000 for further details). The correlation coefficient for each geoclimatic variable and the percentage of covariation for the first two PLS vectors, explaining more than $90 \%$ of variation, were calculated using MorphoJ 1.02d (Klingenberg 2008).

\section{Size analysis}

Centroid sizes of the ventral, dorsal and lateral skull views and the centroid sizes of the ventral and lateral views of the bullae were calculated using PAST (Bookstein 1991). Since the calculated sizes based on the different landmark configurations could be different, the size analyses were done on different size variables, namely: centroid size of the complete skull (were calculated for the three views separately), centroid size of the bulla in ventral view (described by landmarks 12,13 and both open circles), centroid size of the bulla in lateral view (described by landmarks 14, 18, 19, 22 and the open circle), and the relative bulla size with respect to the skull size (as calculated for both the ventral and lateral views). Inter-group skull and bulla size differences between all the $M$. crassus groups, as defined for the shape analysis at an intra-specific level, and M. libycus were tested by a Kruskal-Wallis test (with Bonferroni correction) using PAST. As the ventral cranium contains a larger number of evolutionarily independent components of variation (Caumul \& Polly 2005) as well as the main part of the tympanic bulla, only the size differences obtained from the ventral view are plotted in Fig. 5.

The correlations between the bulla size (which explained the main observed cranial difference at the intraspecific level) and the geoclimatic variables were explored using STATISTICA.

\section{Results}

\section{Interspecific shape differences}

The highly significant Hotelling's $p$-values ( $p<0.001$, Bonferroni corrected) from the classifier analysis of two species shows that only one specimen (type of Meriones libycus gaetulus Lataste, 1882) was misclassified and all other specimens were correctly classified to their a priori defined groups.

The plot of the principal component scores (RW1 vs RW2, Fig. 3) demonstrates that type specimens clustered within the specimens identified as the corresponding species (based on Musser \& Carleton 2005). It also shows that skulls of Meriones libycus are slightly different from those of M. crassus, except for those of the Western Zagros. With respect to the shape variation explained by RW1 (mainly representing bulla inflation), these specimens show an intermediate shape in all the skull views. For the RW2 scores, the Western Zagros specimens are within the upper range of the M. crassus scores for the dorsal view, but not for the ventral and the lateral views.

In ventral view, the tympanic bulla protrudes laterally and rostrally with increasing RW1-value, (landmarks 12 and 13). Also, the zygomatic arch becomes slightly less convex (landmarks 16 and 19). Shape variation explained by the second principal component involves the zygomatic arch becoming 
more convex (landmarks 16 and 19) and the braincase becoming narrower, with RW2-scores going in a positive direction.

In dorsal view, when moving from negative to positive RW1-values, the tympanic bulla becomes substantially inflated, thereby markedly protruding rostrally and laterally (landmarks 15 and 16). Also the interparietal and occipital regions change, becoming distinctly narrower (landmarks 18 and 19). The lateral part of the zygomatic plate protrudes slightly rostrally (landmark 9). With increasing RW2scores, the premaxilla (landmark 7) shifts slightly rostrally, the zygomatic plate shifts slightly laterally (landmark 9), and the interorbital portion of the skull roof becomes narrower (landmarks 10, 11 and 12).

In lateral view (graph not included), also along the first principal component, the tympanic bulla shows a substantial inflation. The distinction, however, of the OTU's is not as clear as the dorsal view data show. Although the ventral view does not reveal a clear distinction either, the results are incorporated in this study, as the ventral cranium contains a larger number of evolutionarily independent components of variation and is known to be the most informative view (Dobigny et al. 2002; Caumul \& Polly 2005).

Looking at the general pattern of shape variation, patterns of skull shape variation (in dorsal and ventral view) are clearly different at inter- versus intraspecific level. Interspecific variation explained by RW1
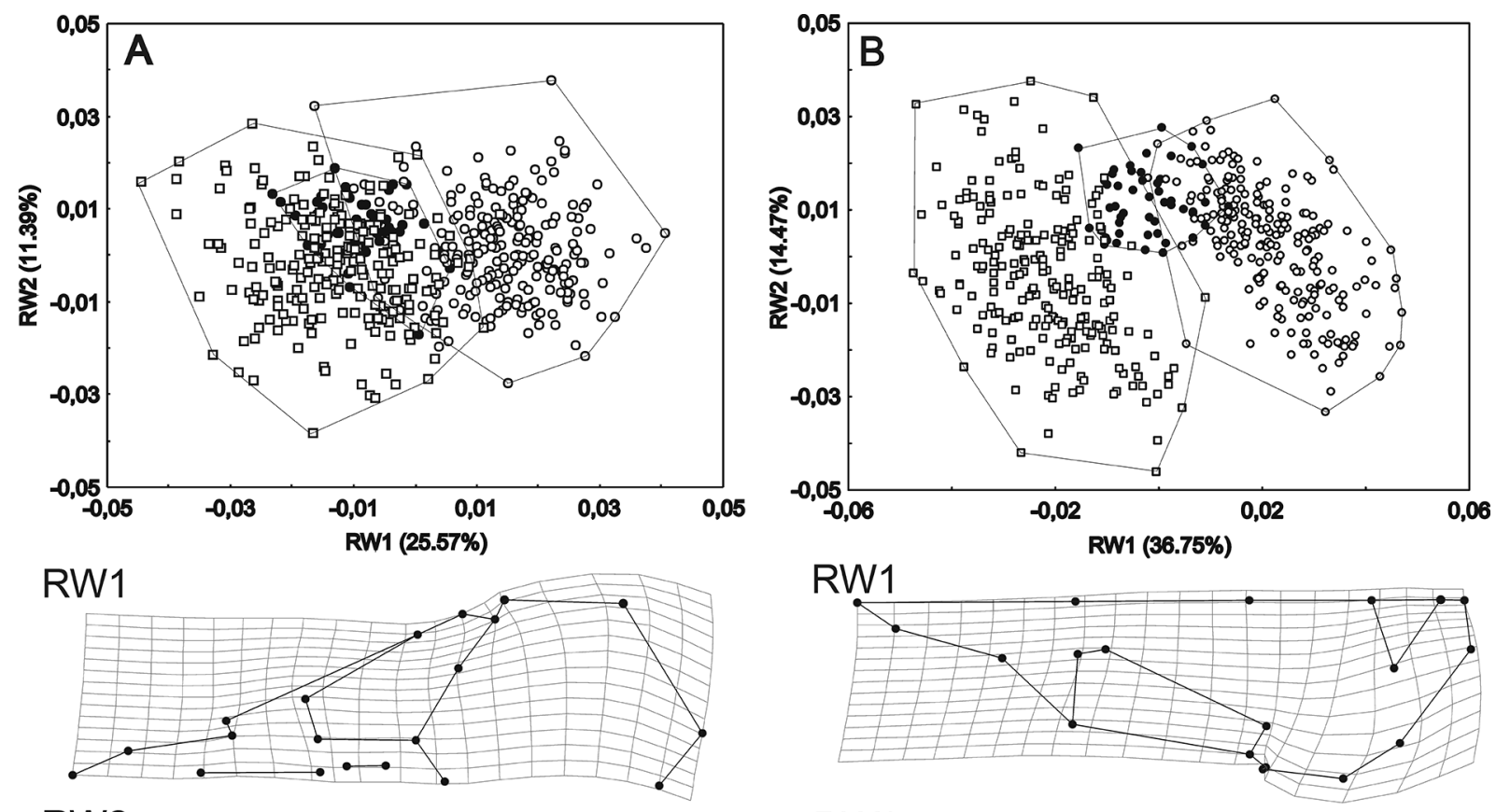

RW2
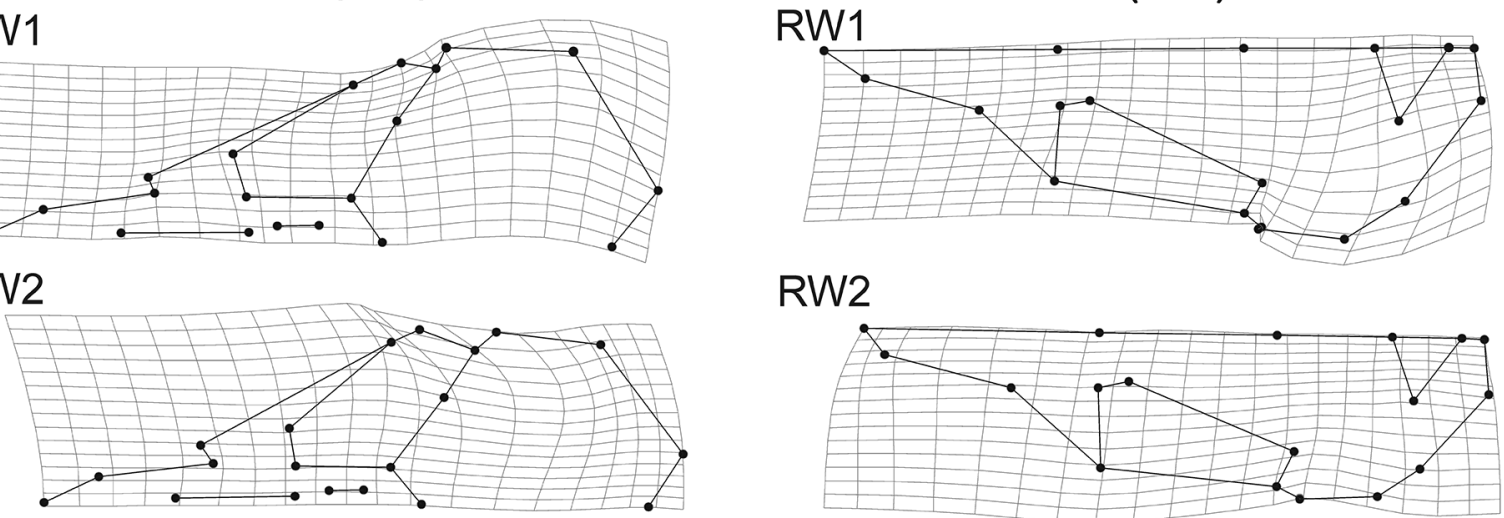

RW2

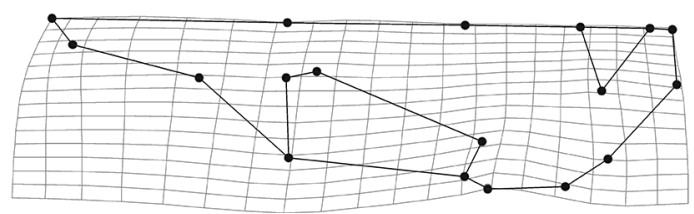

Fig. 3. Scatter plot of RW1 versus RW2 of the (A) ventral and (B) dorsal cranium of Meriones crassus Sundevall, 1842 and M. libycus Lichtenstein, 1823. Legends: $\bigcirc=$ M. crassus (other than Western Zagros), $\bullet=$ M. crassus of Western Zagros, $\square=$ M. libycus. Below: thin-plate spline deformation grids visualize shape variation as expressed by the first two RWs axes (grids represent shape difference between configurations corresponding to lowest and highest RW-values). For the numbering of landmarks, see Fig. 2. 
Table 2. Results of the Monte Carlo simulation test for pairwise comparisons based on Euclidean distances between the group means based on 10000 randomizations $\left({ }^{*} \mathrm{p}<0.0001\right)$. WZ: Western Zagros. 'M. crassus' refers to specimens not from Western Zagros.

\begin{tabular}{|l|l|l|l|}
\hline Pairwise grouping & Ventral & Dorsal & Lateral \\
\hline M. crassus - M. crassus WZ & $0.0269^{*}$ & $0.0335^{*}$ & $0.0384^{*}$ \\
\hline M. crassus - M. libycus & $0.0288^{*}$ & $0.0447^{*}$ & $0.0436^{*}$ \\
\hline M. crassus WZ - M. libycus & $0.0190^{*}$ & $0.0318^{*}$ & $0.0278^{*}$ \\
\hline
\end{tabular}

reflects mainly variation in bulla width. At the intraspecific level (RW2), variation is more constrained (especially for the dorsal view) for the M. crassus from the Western Zagros than for those from other locations and for M. libycus (although caution has to be taken due to different sample sizes). As such, the latter M. crassus and M. libycus show variation in the antero-posterior position of the meatus more than M. crassus from the Western Zagros.

The NPMANOVA revealed a highly significant difference between the OTU's $(\mathrm{p}<0.001)$, with $\mathrm{F}_{72,908}=40.7, \mathrm{~F}_{70,910}=88.0$ and $\mathrm{F}_{82,886}=58.2$ for the ventral, dorsal and lateral shape datasets, respectively. The post-hoc testing showed that all groups are significantly different from each other, thus including both $M$. crassus groups (Table 2). The groups are well separated in CV1-CV2 morphospace, except for four specimens clustering within the Western Zagros group (the M. c. longifrons specimens from Jeddah, Fig. 4).

In ventral view, Western Zagros M. crassus show clear differences with regard to other $M$. crassus specimens (Fig. 4A1). They have a markedly less inflated tympanic bulla, a more convex zygomatic arch (landmarks 16 and 19), a broader zygomatic plate and a facial tuber being positioned laterally (landmark 17). Compared to M. libycus (Fig. 4A2), Western Zagros M. crassus show a bulla that is slightly inflated caudally (landmarks 12 and 13); their zygomatic arch is more convex, the incisive foramen is longer and the palatine fissure becomes slightly longer (landmarks 3 and 4 ) and relatively closer to the tooth row.

In dorsal view, the Western Zagros M. crassus, as compared to other M. crassus specimens, show a clearly less inflated tympanic bulla (landmarks 15 and 16). In the Western Zagros M. crassus specimens, the zygomatic plate is positioned more anteriorly (landmarks 9 and 10) (Fig. 4B1). In the latter group, as compared to M. libycus (Fig. 4B2), the bulla is more inflated and protruded rostrally and toward the zygomatic process of the squamous part, the lateral edges of the zygomatic plate and premaxilla lie more rostrally (landmarks 7 and 9) and the inter-orbital part of the cranial roof is narrower (Fig. 4).

Based on the lateral shape, the tympanic bulla is clearly less inflated in the Western Zagros M. crassus as compared to the other $M$. crassus specimens, where the former group shows a tendency for the suprameatal triangle to close posteriorly (landmarks 15 and 16) and the zygomatic plate to be positioned caudally (landmark 4). Compared to the condition in the M. libycus group, the posterior process of the suprameatal triangle becomes more open and the skull in the bulla part becomes less high in the Western Zagros specimens (not illustrated).

The Monte Carlo simulation on the pooled data from all views (ventral, lateral and dorsal) indicates that all three groups are significantly different from one another $(\mathrm{p}<0.0001)$.

\section{Size differences between $M$. libycus and the M. crassus groups}

The results of a Kruskal-Wallis test on skull size (with centroid size obtained from all three skull views) revealed significant $(\mathrm{p}<0.0001)$ inter-group differences among M. crassus and M. libycus. Bulla size 
was also significantly different $(\mathrm{p}<0.0001)$ between the groups in ventral and lateral views, both in absolute and relative terms (relative to the skull size).

The Kruskal-Wallis test on the ventral skull size data shows a significant difference between the $M$. crassus from the Western Zagros and those from the Iranian Plateau, with the latter having significantly smaller skulls (Fig. 5A). The M. crassus from the Western Zagros and M. libycus have a significantly larger cranium $(\mathrm{p}<0.05)$, with the latter having the largest. The Western Zagros group is not different from the Arabian and African groups ( $\mathrm{p}>0.05$ ). For the absolute bulla size (both ventral and lateral data, not illustrated here), the M. crassus from the Western Zagros and those from the Iranian Plateau do not show a significant difference $(p>0.05)$. However, they show a significantly smaller bulla size compared to the other groups $(\mathrm{p}<0.05)$, which could be the consequence of the overall small skull size in the M. crassus specimens from the Iranian Plateau. The Western Zagros M. crassus specimens have a smaller, though not significantly, relative bulla size than the M. libycus specimens ( $\mathrm{p}>0.05)$ (Fig. 5B). The Iranian Plateau specimens have the largest relative bulla size, being significantly different from all the other groups $(\mathrm{p}<0.05)$ except the Arabian group $(\mathrm{p}=0.062)($ Fig. 5B).
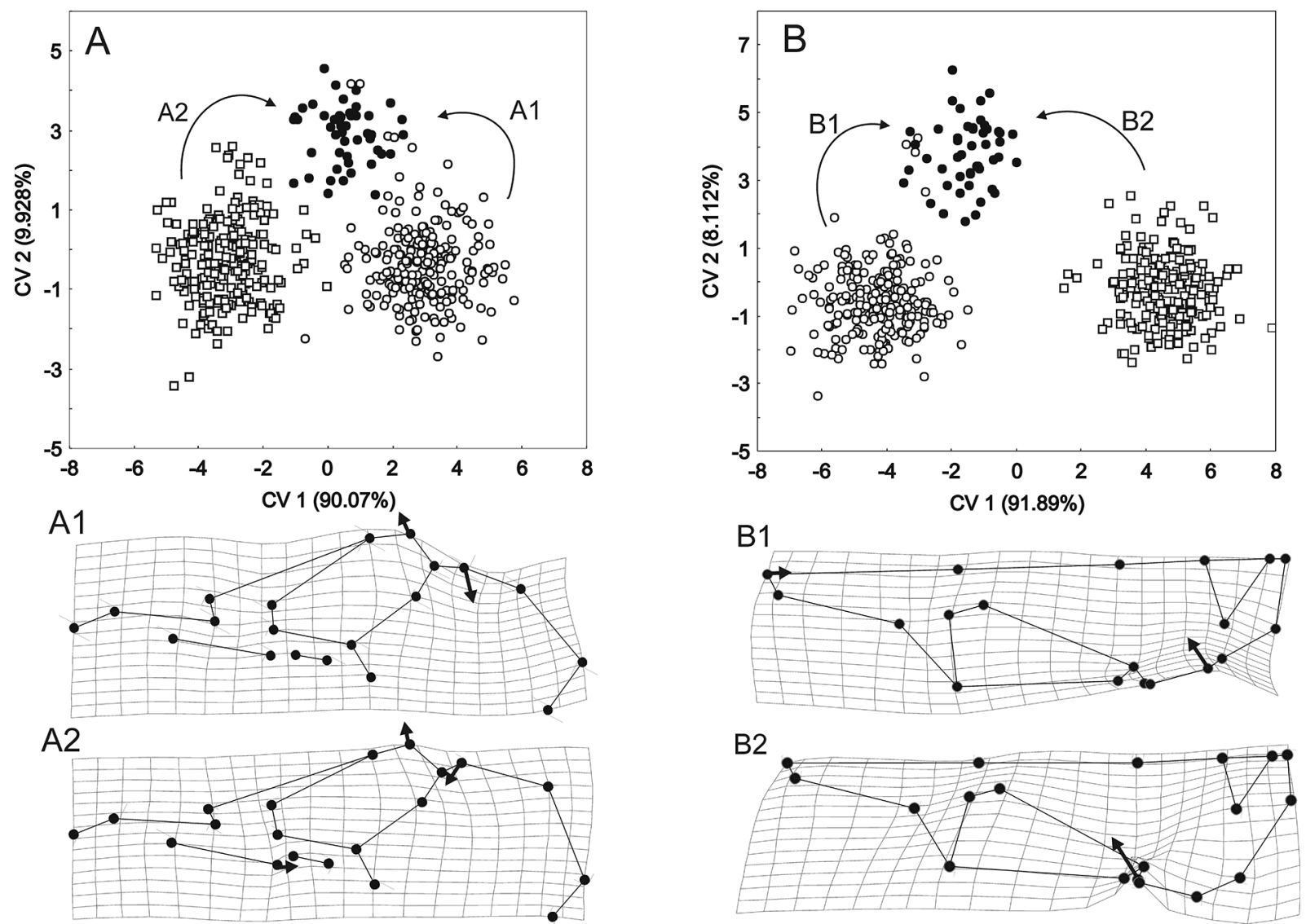

Fig. 4. Scatter plot of the CVA results of the (A) ventral and (B) dorsal shape data of Meriones crassus Sundevall, 1842 (two groups) and M. libycus Lichtenstein, 1823. Legends: $\bigcirc=$ M. crassus (other than Western Zagros), $\bullet=$ M. crassus of Western Zagros, $\square=$ M. libycus. The grids below show deformation along the arrows, when moving from the M. crassus group mean shape to the Western Zagros group mean shape (A1 and B1), and from the M. libycus mean shape to the mean shape of the Western Zagros (A2 and B2) (shape differences magnified three times for better visualization). For the numbering of landmarks, see Fig. 2. 


\section{Patterns of intraspecific shape variation in M. crassus}

The plot of the first two principal components shows three groups that can more or less be separated from each other (Fig. 6): (A) the Iranian Plateau group, (B) the Western Zagros group and (C) the African group with the Arabian specimens and those from Kuwait, Jordan and NW Arabia scattered around them.

The first two principal components account for almost $40 \%$ of the total shape variation and show that the Western Zagros specimens have low RW1-scores (mainly corresponding to having a less inflated bulla) compared to the other groups and occupy a somewhat distinct part of morphospace (Fig. 6). Within the $M$. crassus morphospace, the following shape changes are the most obvious (as explained by RW1 and RW2, Fig. 6): in ventral view, the specimens from the Iranian Plateau (with highest RW1-scores) are characterized by a tympanic bulla being more inflated and protruding laterally and rostrally (landmarks 13, 14 and 15) and a zygomatic arch being less convex (landmarks 16 and 19). The specimens with higher RW2-scores, mostly from the Iranian Plateau and the Western Zagros Mountain and Jeddah, are characterized by a less convex zygomatic arch, but with the most lateral point of the zygomatic arch being positioned more rostrally (landmarks 16 and 19) and the zygomatic plate being less wide (landmarks 17 and 18).

For the dorsal view (Fig. 6B), specimens from the Iranian Plateau have the highest RW1-scores and are characterized by a substantially inflated tympanic bulla that protrudes rostrally and more laterally (landmarks 15 and 16) and a narrower cranium at the level of the zygomatic plates and occiput. The high RW2-scores for specimens from the Western Zagros and the Iranian Plateau reflect a lateral compression of the zygomatic process of the squamous and tympanic bulla (landmarks 14, 15, 16 and 12), and a less convex zygomatic plate (landmarks 9 and 8 ).

For the lateral view (Fig. 6C), the Western Zagros and Jeddah groups cluster together and lie separate from the other groups. The latter have high RW1-scores, reflecting a more inflated bulla protruding rostrally (landmarks 10 to 14 and 22) and a substantially wider suprameatal triangle with completely open posterior processes (landmarks 15 and 16 shifted away from each other). With increasing RW2scores, the skull roof becomes less convex (the posterior part of the skull shifts caudodorsally and the rostral part shifts dorsally as well).
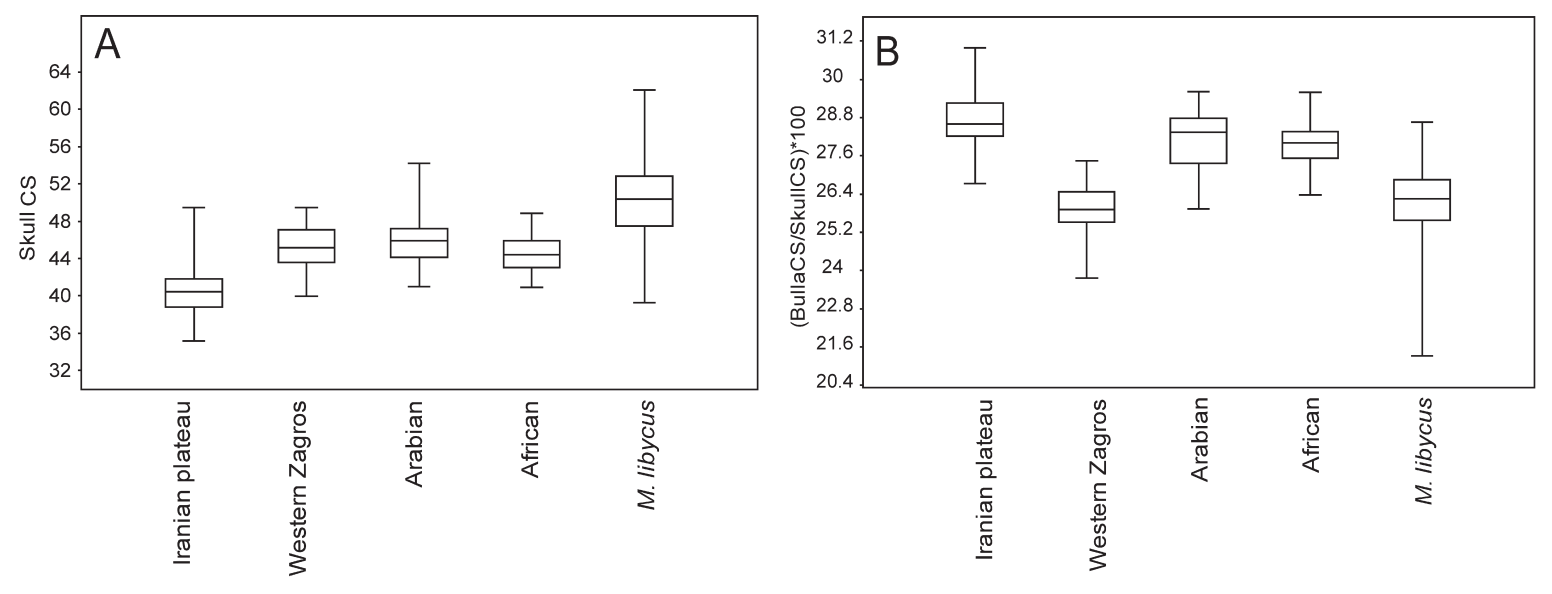

Fig. 5. Box-and-whisker plots of (A) skull size and (B) relative bulla size of the ventral cranium. The boxes indicate the $25-75 \%$ quartiles; the whiskers represent the minimal and maximal values. 

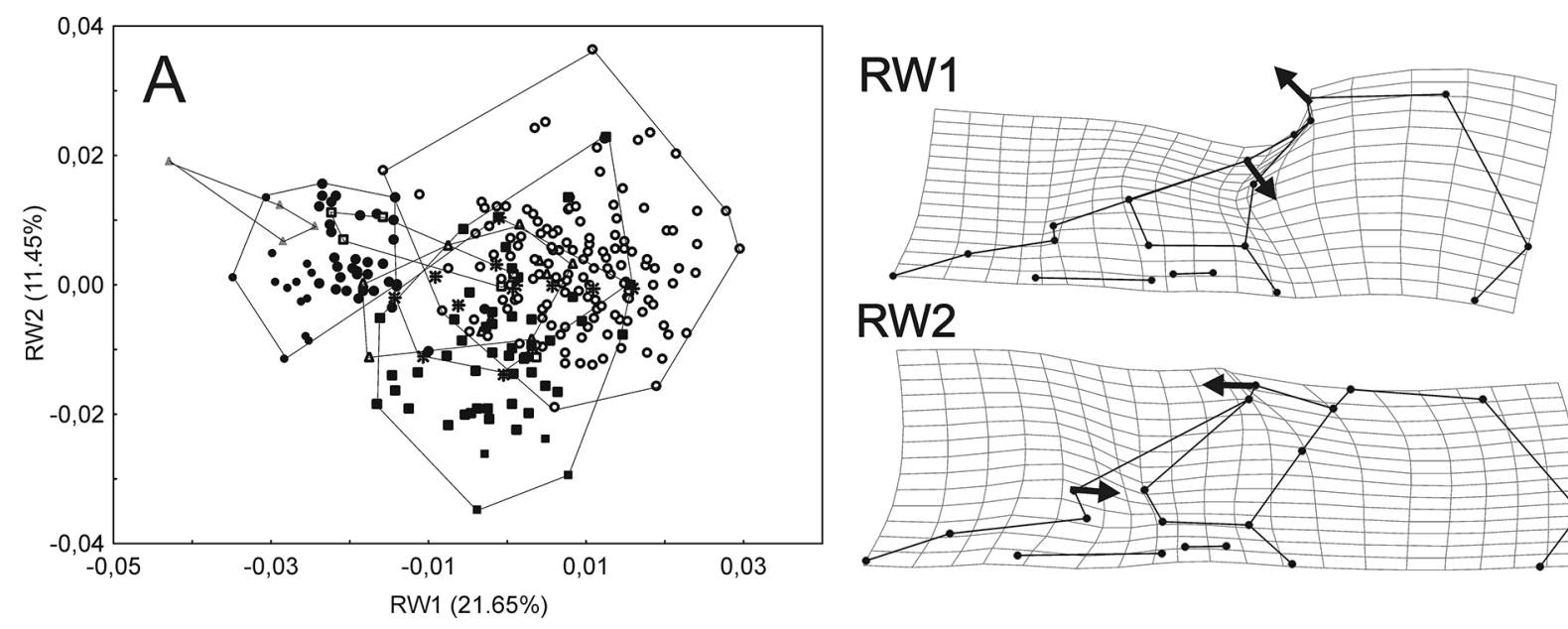

RW2
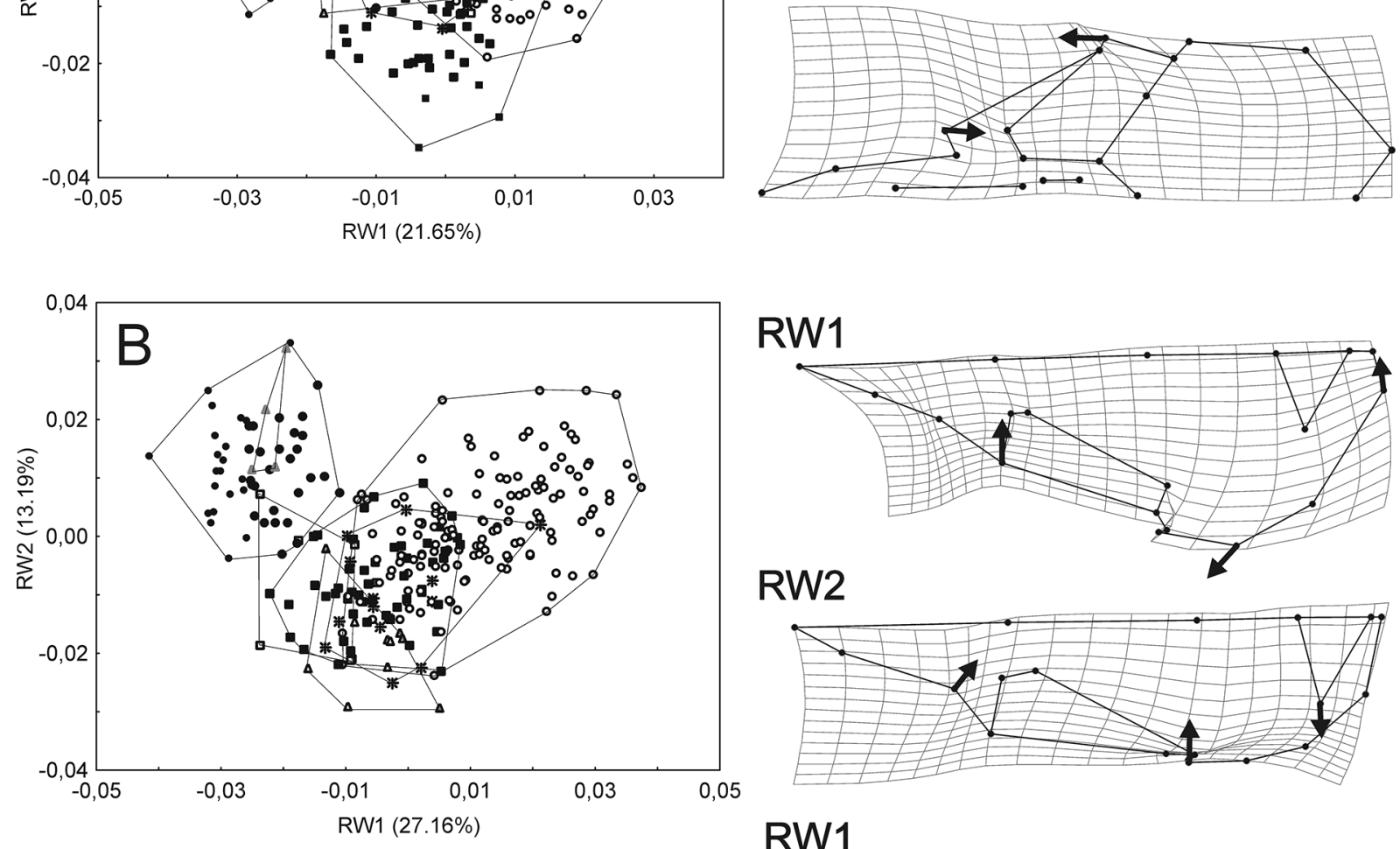

\section{RW2}
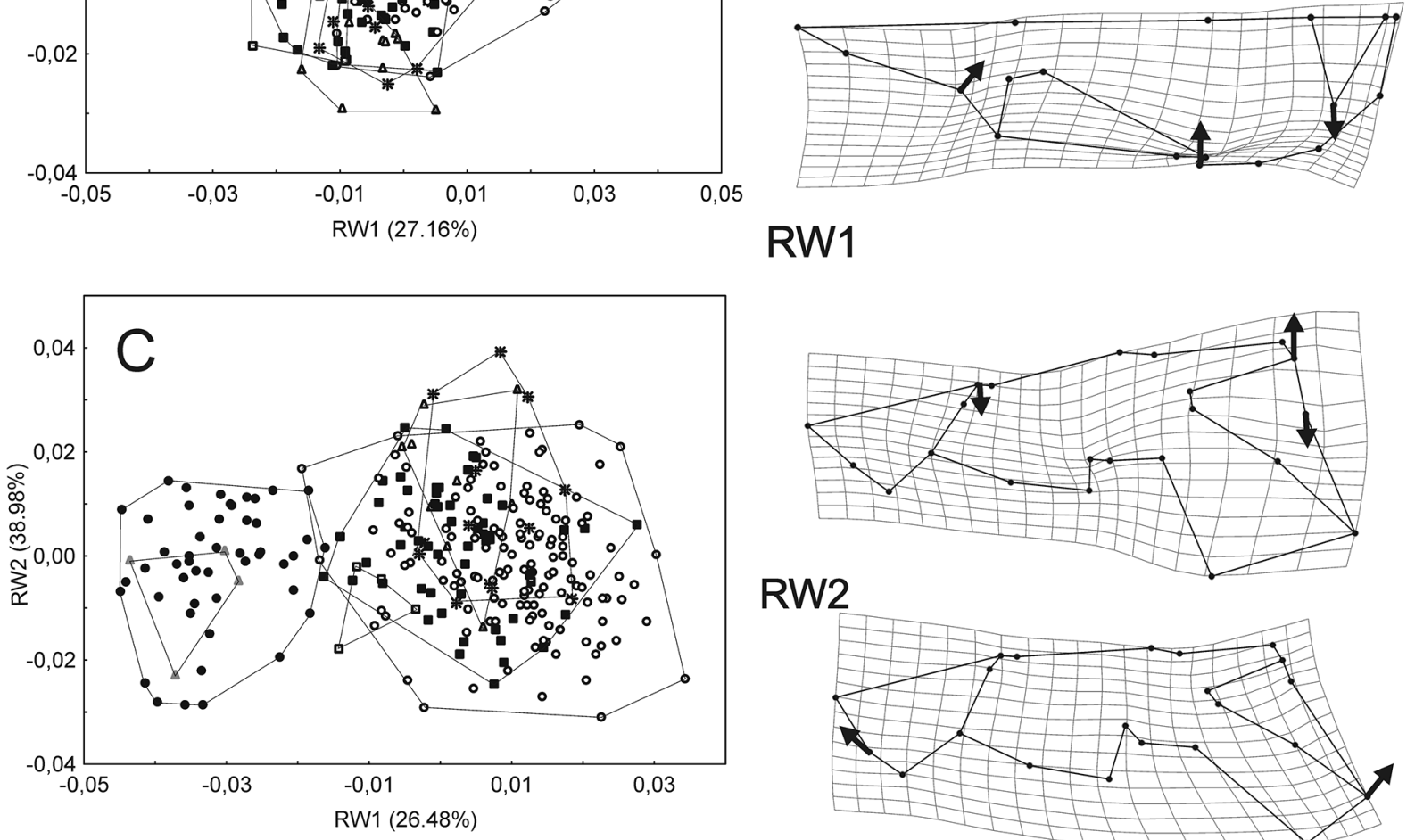

RW1

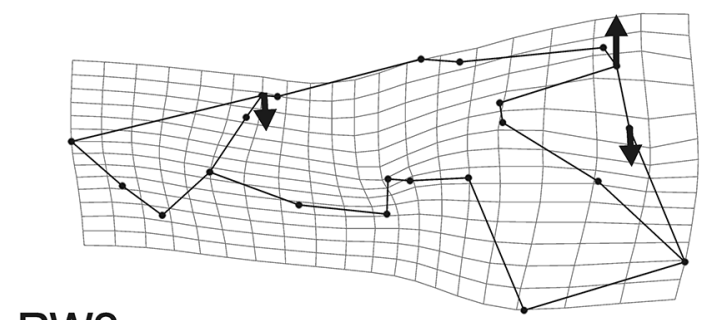

RW2

Fig. 6. Scatter plot of PCA results on shape variables of the (A) ventral, (B) dorsal and (C) lateral sides of Meriones crassus Sundevall, 1842 specimens. Legends: $\bigcirc=$ Iranian Plateau, $\bullet=$ Western Zagros, $*=$ Kuwait, $\Delta=$ Arabian, $\Delta=$ Jeddah, $\square=$ Jordan/NW Arabia, $\boldsymbol{\square}=$ African. Deformation grids (two times magnified) along the first principal components, representing shape differences between configurations corresponding to minimal and maximal scores, are shown to the right of each plot. For the numbering of landmarks, see Fig. 2. 
The highly significant Hotelling's $p$-values (Bonferroni corrected) from the classifier analysis $(\mathrm{p}<0.001)$ shows that most specimens were correctly assigned to their a priori defined M. crassus groups (Iranian Plateau specimens: $98 \%$, Western Zagros specimens: $100 \%$, Arabian specimens: $69 \%$ and African specimens: $86 \%$ ).

The CVA ordination shows that the Western Zagros group is clearly separated from the other groups by CV1 (Fig. 7). The Iranian Plateau group and the African groups are also fairly well separated from each other along CV2.

For the ventral shape, when comparing the consensus of the Western Zagros group with that of the African group (Fig. 7A1), the former has a less inflated tympanic bulla (landmarks 12 and 13) and the zygomatic plate is slightly narrower (landmarks 17, 18 and 20). When the Western Zagros consensus is compared to that of the Iranian Plateau group (Fig. 7A2), the tympanic bulla is less inflated (landmarks12 and 13), the zygomatic arch is more convex (landmarks 16 and 19), and the temporal bone is positioned more caudally (landmarks 14 and 15 are positioned more toward the median line and caudally).

When comparing the Western Zagros and the African groups, with regard to the dorsal shape consensus, it is found that the former has a tympanic bulla that is clearly less inflated (landmarks 15 and 16), the zygomatic process of the squamosal is narrower (landmarks 12 and 14), the interparietal is wider (landmarks 18 and 19), and as the bulla is less inflated, a smaller part of the bulla is visible from a dorsal view. Comparing it to the mean shape of the Iranian Plateau group, the consensus of the Western Zagros group has a less inflated tympanic bulla (landmarks 15 and 16), the zygomatic process of the squamosal
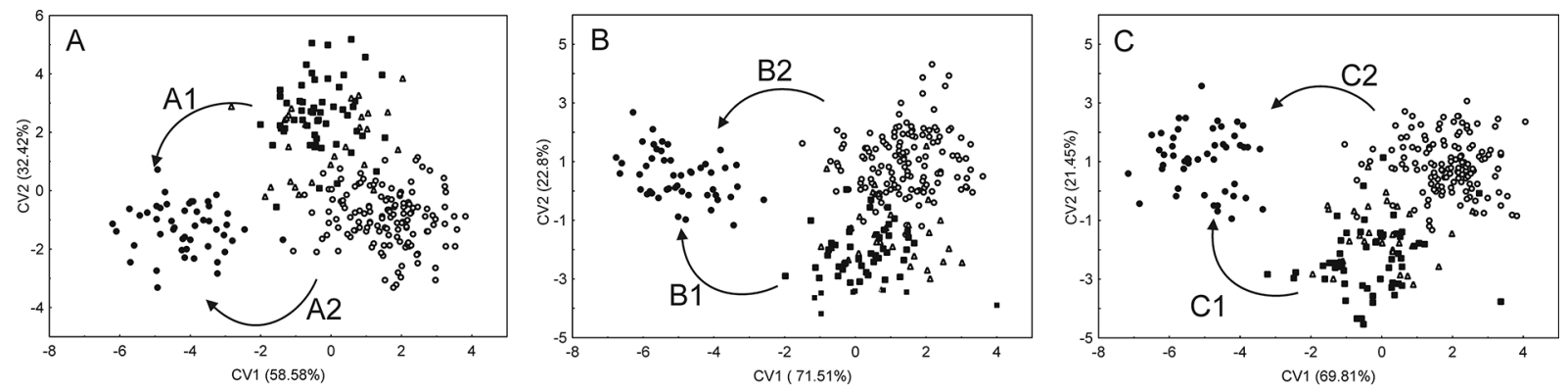

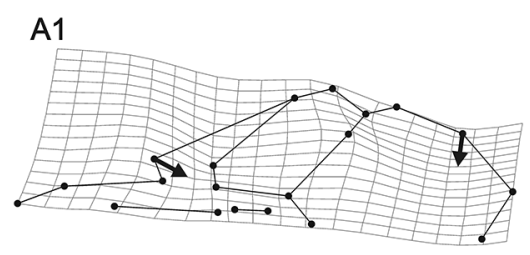

B1

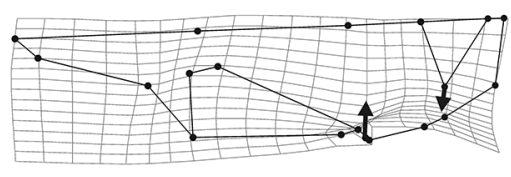

B2

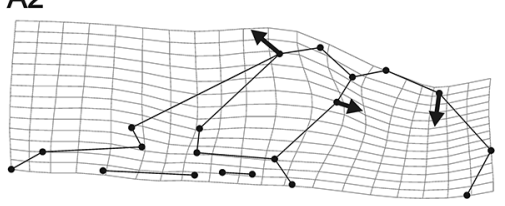

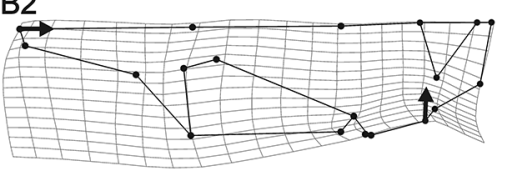

C1

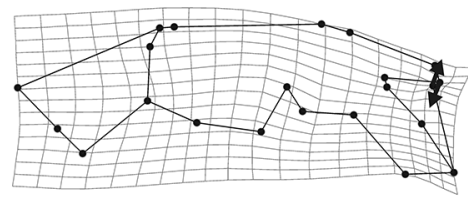

C2

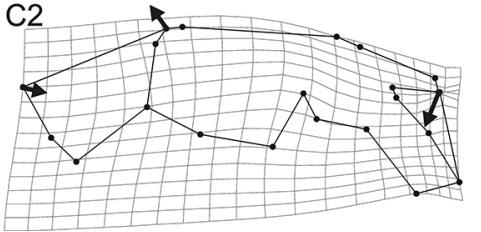

Fig. 7. CVA scatter plot (axes 1 and 2) on shape variables of the (A) ventral, (B) dorsal and (C) lateral side of the Meriones crassus groups (Jeddah group not included). Legends: $\odot=$ Iranian plateau, $\bullet=$ Western Zagros, $\Delta=$ Arabian and $\boldsymbol{m}=$ African. Grids show deformation $(3 \mathrm{x}$ magnified $)$ when following the trajectory within the morphospace along the arrows and between the groups' consensus (from African to Western Zagros - A1, B1 and C1; and from Iranian plateau to Western Zagros - A2, B2 and C2). For the numbering of landmarks, see Fig. 2. 
Table 3. Euclidean distances between the Meriones crassus group mean shapes obtained from the Monte Carlo pairwise comparisons $(* \mathrm{p}<0.01, * * \mathrm{p}<0.001)$.

\begin{tabular}{|l|c|c|c|}
\hline Pairwise grouping & Ventral & Dorsal & Lateral \\
\hline Iranian plateau-Western Zagros & $0.0192^{* *}$ & $0.0222^{* *}$ & $0.0415^{* *}$ \\
\hline Iranian plateau-Arabian & $0.0095^{*}$ & $0.0212^{* *}$ & $0.0193^{* *}$ \\
\hline Iranian plateau-African & $0.0127^{* *}$ & $0.0309^{* *}$ & $0.0190^{* *}$ \\
\hline Western Zagros-Arabian & $0.0152^{* *}$ & $0.0287^{* *}$ & $0.0355^{* *}$ \\
\hline Western Zagros-African & $0.0171^{* *}$ & $0.0123^{* *}$ & $0.0351^{* *}$ \\
\hline Arabian-African & 0.0080 & $0.0222^{*}$ & $0.0174^{* *}$ \\
\hline
\end{tabular}

extends more laterally (landmarks 13 and 14), the nasal tip is projected less rostrally, and the premaxilla is positioned more rostrally (landmarks 1 and 7).

Compared to the consensus of the African group, the lateral face of the skull of the Western Zagros group (Fig. 7C1) has a less inflated bulla, the suprameatal triangle shows a tendency to close dorsally and the zygomatic plate tends to move caudally (landmark 4). Compared to the Iranian Plateau group (Fig. 7C2), changes in the bulla follow the same pattern as described in Fig. 7C1, but the posterior processes of the suprameatal triangle are more closed in the Western Zagros consensus; the skull is higher at the level of the maxillary part, and the nasal is shorter.

The MANOVA reveals a high level of morphological differentiations among the $M$. crassus groups $(\mathrm{p}<0.001)$ with $\mathrm{F}_{108687}=13.83, \mathrm{~F}_{102960}=13.64$ and $\mathrm{F}_{120675}=13.75$ for the ventral, dorsal and lateral shape datasets, respectively. The pair-wise comparisons show that all the $M$. crassus groups are significantly different from each other, except for the Arabian and African ones (ventral view, Table 3). The Monte Carlo test on the pooled data supports an overall cranial shape difference between these groups as well $(\mathrm{p}<0.001)$.

In both the UPGMA and NJ analyses, three major clusters emerge, though comprising different groups. In the NJ dendogram, a Western Arabian + Iranian cluster is observed, which is more similar to the African group rather than to the Eastern Arabian group (including Kuwait). The UPGMA, however, suggests a closer morphological affinity between the Eastern and NW Arabian groups, in which the

A

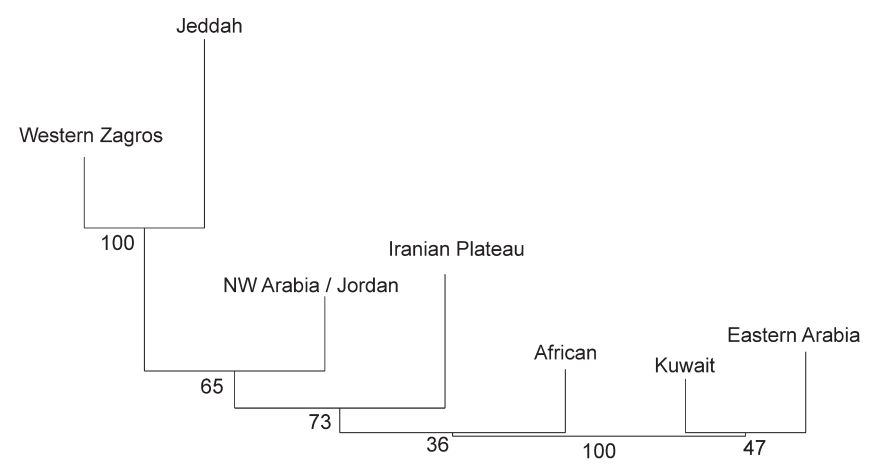

B

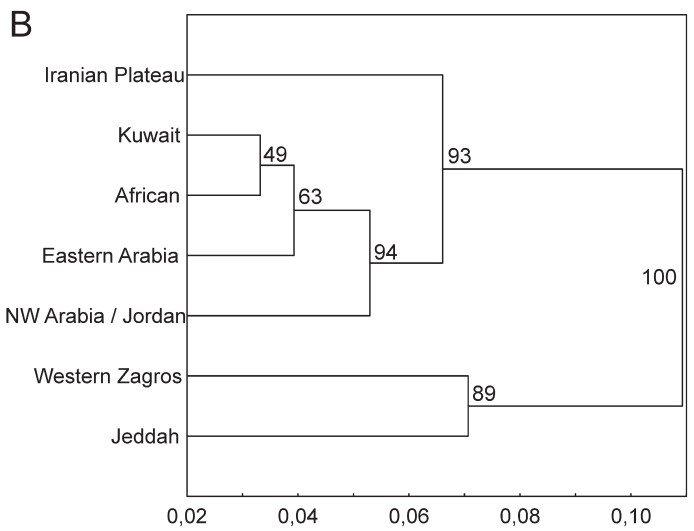

Fig. 8. Dendograms obtained from the (A) NJ clustering and (B) UPGMA, using Euclidean distances between group means by combining all data (shape information from dorsal, ventral and lateral views). Branch bootstrap support shown at the nodes, 10000 replicates. 
Table 4. The 2B-PLS results derived from species-specific analyses in Meriones crassus Sundevall, 1842 and M. libycus Lichtenstein, 1823. The relationship between each of the first two vectors and the geoclimatic variables are represented by the correlation coefficient and the percentage of covariation $\left({ }^{*} \mathrm{p}<0.05\right)$.

\begin{tabular}{|l|c|c|c|c|}
\hline & \multicolumn{2}{|c|}{ M. crassus } & \multicolumn{2}{c|}{ M. libycus } \\
\hline Variable & $\mathbf{1}$ & $\mathbf{2}$ & $\mathbf{1}$ & $\mathbf{2}$ \\
\hline Elevation (m) & -0.554 & -0.141 & -0.065 & -0.586 \\
\hline Rainfall $(\mathbf{m m})$ & -0.115 & 0.684 & -0.275 & 0.482 \\
\hline Mean T $\left({ }^{\circ} \mathbf{C}\right)$ & 0.541 & -0.024 & 0.561 & 0.290 \\
\hline Max T $\left({ }^{\circ} \mathbf{C}\right)$ & 0.463 & -0.299 & 0.099 & 0.436 \\
\hline Min T $\left({ }^{\circ} \mathbf{C}\right)$ & 0.415 & 0.340 & 0.637 & 0.083 \\
\hline \% cov explained & $80.544 *$ & $12.234^{*}$ & $57.987 *$ & $26.966^{*}$ \\
\hline
\end{tabular}

African group lies nested. As in the NJ, the Western Zagros and Jeddah groups are very similar, but are most distinct from all other groups based on the UPGMA. Based on these rather conflicting results, it is difficult to draw any conclusion, although the UPGMA results are supported by higher bootstrap values. Still, both analyses show that the Western Zagros and Jeddah group do form a distinct group.

The MANCOVA results show that even when taking size variation between the $M$. crassus groups into account, they are still significantly different in shape (Wilks' lambda $=0.067$, F-value $=6.723$; $\mathrm{p}=0.000$ ). The results show that there is no apparent sexual dimorphism in shape when considering the size-related variation (Wilks' lambda $=0.846, \mathrm{~F}$-value $=0.982 ; \mathrm{p}=0.51$ ), but there is an interaction effect of group on sex (Wilks' lambda $=0.522$, F-value $=1.3 ; \mathrm{p}=0.018$ ). This means sex and group (together) have been affected the observed inter-group differences in M. crassus.

\section{Geoclimatic correlations with cranial variation}

Testing the association between the morphological variation and the geoclimatic variation shows that only in $M$. crassus is there a tendency for correlation of bulla size with elevation, but not with rainfall. No correlation for either of these geoclimatic variables is observed in M. libycus (Table 4). Overall skull shape variation in $M$. crassus proved to be mainly correlated with elevation and temperature, versus with temperature and rainfall in M. libycus (Table 4).

\section{Discussion}

\section{Is the Meriones crassus from Western Zagros phenotypically distinct?}

The analyses of the separate datasets (ventral, dorsal and lateral views) show that the distinction between M. crassus and M. libycus is not always clear. However, the pooled data show that they are significantly different in their overall skull shape, especially at the level of the dorsal view. Moreover, the investigation of the phenotypic variation within the entire geographic range of $M$. crassus shows that the specimens from the Iranian Plateau reveal a considerably distinct cranial form. It also shows that the African and Arabic populations seem more similar to those from the Iranian Plateau, although being geographically more distant. The results thus clearly support the hypothesis that M. crassus from Western Zagros has a distinct cranial phenotype, which could indicate that it is a separate natural group (see below). Since M. crassus of the Western Zagros is morphologically (cranial size and external characters) distinct from M. libycus, and since M. libycus co-occurs with M. crassus in the Khouzestan Plain and Mesopotamia, it can be excluded from being synonymous. This difference is most pronounced in the dorsal skull view. It could also be confirmed that the observed shape differences were not just correlated with the cranial differences in size, where $M$. libycus has a substantially larger skull than the $M$. crassus groups. 
Looking at skull size, specimens from the Western Zagros represent a unique configuration in having a significantly smaller skull compared to that of M. libycus, although they are not different in the relative size of the bulla (Fig. 5). This is in contrast to the other M. crassus specimens, that clearly have larger relative bulla sizes (Fig. 5B). The observed small bulla size in M. crassus from the Western Zagros corresponds with the observations by Petter (1961) and Thomas (1919). Our observations also seem to confirm that, in agreement with Thomas (1919) and Harrison (1972), Jeddah specimens have a skull shape most similar to those of the Western Zagros specimens. Still, this does not provide sufficient support to make any further claims about the taxonomic status of $M$. c. longifrons, a subspecies described, based on specimens from Jeddah, as this requires further research on a larger sample.

\section{Do Meriones crassus from Western Zagros form a distinct geographical and natural group?}

Considering the apparent geographical isolation of the Western Zagros group from the other Iranian M. crassus, it must be noted that the Khuzestan Plain, where M. crassus specimens from the Western Zagros are distributed, is geographically separated from the Iranian Plateau by the Zagros Mountains (they form the Iranian Plateau's western boundary with eastern Mesopotamia).

The analyses in this study (e.g. the cluster analysis) clearly support the hypothesis that the Western Zagros group represents a distinct group (not considering the Jeddah group, see previous paragraph) and also confirmed the dimorphic nature of the skull shape within Iranian populations of $M$. crassus. It can thus be concluded that the Western Zagros M. crassus is both morphologically (mainly in having a less swollen bulla and darker, pinkish buff fur) and geographically distinct from other Iranian populations of Meriones crassus. Whether or not this now reflects reproductive isolation, and hence the result of a recent or ongoing speciation event, cannot be ascertained based on our data. Population genetic and phylogenetical studies should be carried out to verify this.

\section{Geoclimatic correlation of the morphological variation}

The impact of environmental factors, especially aridity, on the morphological variation in jirds has long been recognized, thereby to some degree explaining patterns of inter- and intraspecific morphological differences (e.g. Petter 1961; Sénégas 2001; Chevret \& Dobigny 2005; Darvish 2009; Pavlinov et al. 2010; Tabatabaei Yazdi \& Adriaens 2011; Tabatabaei Yazdi et al. 2012). This is confirmed in our study, where the covariation between the bulla and environmental factors is prominent. The increase in tympanic bulla size can be considered to be adaptive (Lay 1972; Webster \& Webster 1984; Van der Straeten \& Dieterlen 1992; Webster \& Plassmann 1992; Huang et al. 2002), as it causes an increased amplification of sound that allows rodents to increase low-frequency hearing and detect an approaching predator more rapidly (Burda et al. 1990; Mason 2001, 2003; Huang et al. 2002; Schleich \& Vasallo 2003). As such, a bulla hypertrophy may reflect a morphological adaptation for efficient vocal communication in a desert environment, where rodent population densities are low, and in an underground environment as well (Petter 1961; Harrison 1972; Lay 1972; Darvish 2009; Colangelo et al. 2010). This is corroborated by Vaughan et al. (2000) and our study, as smaller tympanic bullae were found in populations occurring in regions with higher levels of rainfall (and vice versa). Smaller bullae were found in specimens occurring in the lowlands of the Khuzestan Plain and Mesopotamia, which have a high humidity during the summer and higher annual rainfall (ranges from 250 to $500 \mathrm{~mm}$; Britannica Online Encyclopedia, FAO 2007). Considering that climatic conditions in the Khuzestan Plain and Jeddah habitats are similar, the observed morphological similarities between specimens originating from these localities could reflect convergent phenotypes. Additionally, specimens originating from the Iranian Plateau, where drier climatic conditions exist, have larger bullae (in most of the country, yearly precipitation averages $250 \mathrm{~mm}$ or less; Firouz 2005). 


\section{The need for a revision of identification keys}

The manifest intraspecific and climate-dependent morphological plasticity in the skulls of the studied jird species (especially involving the bulla hypertrophy and suprameatal triangle condition) is often used as an important diagnostic character in regional identification keys (e.g., Chaworth-Muster \& Ellerman 1947). It is clear from this study, that these keys mostly do not take the natural range of intraspecific variability into account. Hence, they should be used with caution and are in need of revision.

\section{Acknowledgments}

We are very grateful to J. Darvish (Ferdowsi University of Mashhad), M.D. Carleton (USNM), L.R. Heaney (FMNH), J. Cuisin (MNHN) and P. Jenkin and R. Portela Miguez (BMNH), for providing us access to their collections. Thanks to Tom Greeninckx and the anonymous referees of earlier drafts of this manuscript for their valuable comments and assistance in improving this article.

\section{References}

Adams D.C. \& Rohlf F.J. 2000. Ecological character displacement in Plethodon: Biomechanical differences found from a geometric morphometric study. Proceeding of the Natural Academic of Sciences of the U.S.A. 97 (8): 4106-4111. http://dx.doi.org/10.1073/pnas.97.8.4106

Anderson S.C. 1989. Fauna of Persia. Encyclopedia Iranica 9 (4): 437-446.

Barciova L. \& Macholán M. 2006. Morphometric study of two species of wood mice Apodemus sylvaticus and A. flavicollis (Rodentia: Muridae): traditional and geometric morphometric approach. Acta Theriologica 51 (1): 15-27. http://dx.doi.org/10.1007/BF03192651

Bookstein F.L. 1991. Morphometric Tools for Landmark Data: Geometry and Biology. Cambridge University Press, Cambridge, UK.

Bookstein F.L., Chernoff B., Elder R.L., Humphries J.M., Smith G.R. \& Strauss R.E. 1985. Morphometrics in Evolutionary Biology, the Geometry of Size and Shape Change with Examples from Fishes. Special publication 15, Academy of Natural Sciences, Philadelphia.

Burda H., Bruns V. \& Müller M. 1990. Sensory adaptations in subterranean mammals. Progress in Clinical and Biological Research 335: 269-293.

Cardini A., Jansson A.-U. \& Elton S. 2007. A geometric morphometric approach to the study of clinal variation in vervet monkeys. Journal of Biogeography 34 (10): 1663-1678. http://dx.doi.org/10.1111/ j.1365-2699.2007.01731.x

Caumul R. \& Polly P.D. 2005. Phylogenetic and Environmental Components of Morphological Variation: Skull, Mandible, and Molar Shape in Marmots (Marmota, Rodentia). Evolution 59 (11): 2460-2472. http://dx.doi.org/10.1111/j.0014-3820.2005.tb00955.x

Chaworth-Musters J.L. \& Ellerman J.R. 1947. A Revision of the Genus Meriones. Proceedings of the Zoological Society of London 117 (2-3): 478-504. http://dx.doi.org/10.1111/j.1096-3642.1947.tb00533.x

Chevret P. \& Dobigny G. 2005. Systematics and evolution of the subfamily Gerbillinae (Mammalia, Rodentia, Muridae). Molecular Phylogenetics and Evolution 35 (3): 674-688. http://dx.doi.org/10.1016/j. ympev.2005.01.001

Colangelo P., Castiglia R., Franchini P. \& Solano E. 2010. Pattern of shape variation in the eastern African gerbils of the genus Gerbilliscus (Rodentia, Muridae): Environmental correlations and implication for taxonomy and systematics. Mammalian Biology 75 (4): 302-310. http://dx.doi.org/10.1016/j. $\underline{\text { mambio.2009.05.001 }}$ 
Cordeiro-Estrela P., Baylac M., Denys C. \& Polop J. 2008. Combining geometric morphometrics and pattern recognition to identify interspecific patterns of skull variation: case study in sympatric Argentinian species of the genus Calomys (Rodentia: Cricetidae: Sigmodontinae). Biological Journal of the Linnean Society 94 (2): 365-378. http://dx.doi.org/10.1111/j.1095-8312.2008.00982.x

Darvish J. 2009. Morphometric comparison of fourteen species of the genus Meriones Illiger, 1811 (Gerbillinae, Rodentia) from Asia and North Africa. Iranian Journal of Animal Biosystematics 5 (1): 59-77.

Dobigny G., Baylac M. \& Denys C. 2002. Geometric morphometrics, neural networks and diagnosis of sibling Taterillus species (Rodentia, Gerbillinae). Biological Journal of the Linnean Society 77 (3): 319-327. http://dx.doi.org/10.1046/j.1095-8312.2002.00074.x

Elewa A.M.T. (ed.) 2004. Morphometrics: Applications in Biology and Paleontology. Springer, Berlin.

Ellerman J.R. 1948. Key to the Rodents of South-West Asia in the British Museum. Proceeding of the Zoological Society of London 118 (3): 765-816. http://dx.doi.org/10.1111/j.1096-3642.1948.tb00406.x

Fadda C. \& Corti M. 2001. Three-dimensional geometric morphometrics of Arvicanthis: implications for systematics and taxonomy. Journal of Zoololgical Systematics and Evolutionary Research 39 (4): 235-245. http://dx.doi.org/10.1046/j.1439-0469.2001.00169.x

FAO 2007. FAO World Climate Data [online]. Available from http://freegeographytools.com/2007/faoworld-climate-data [accessed 20 July 2012]

Firouz S. 2005. The Complete Fauna of Iran. I.B. Tauris Publishers, London.

Gower J.C. 1975. Generalized procrustes analysis. Psychometrika 40 (1): 33-51. http://dx.doi. org/10.1007/BF02291478

Hammer Ø., Harper D.A.T. \& Ryan P.D. 2001. PAST: Paleontological Statistics Software Package for Education and Data Analysis. Palaeontologia Electronica 4 (1). Available from http://palaeo-electronica. org/2001_1/past/issue1_01.htm [accessed 20 Jan. 2013]

Harrison D.L. 1956. Gerbils from Iraq, with description of a new gerbil. Journal of Mammalia 37 (3): 417-422. http://dx.doi.org/10.2307/1376743

Harrison D.L. 1972. The Mammals of Arabia. Vol. 3. Lagomorpha, Rodentia. Ernest Been Ltd, London.

Hatt R.T. 1959. The Mammals of Iraq. Miscellaneous Publications 106, Museum of Zoology, University of Michigan, Michigan.

Hood G.M. 2010. PopTools version 3.2.3. Available from http://www.cse.csiro.au/poptools [accessed 20 Aug. 2013]

Huang G.T., Rosowski J.J., Ravicz M.E. \& Peake W.T. 2002. Mammalian ear specializations in arid habitats: structural and functional evidence from sand cat (Felis margarita). Journal of Comparative Physiology A 188 (9): 663-681.

Klingenberg C.P. 2008. MorphoJ. Faculty of Life Sciences, University of Manchester, UK. Available from http://www.flywings.org.uk/MorphoJ_page.htm [accessed 2 Sep. 2012]

Koffler B.R. 1972. Meriones crassus. Mammalian Species 9: 1-4. http://dx.doi.org/10.2307/3504037

Lay D.M. 1967. A Study of the Mammals of Iran, Resulting from the Street Expedition of 1962-63. Fieldiana Zoology 54, Field Museum of Natural History, Chicago. http://dx.doi.org/10.5962/bhl. $\underline{\text { title. } 2961}$ 
Lay D.M. 1972. The Anatomy, Physiology, Functional Significance and Evolution of Specialized Hearing Organs of Gerbilline Rodents. Journal of Morphology 138 (1): 41-120. http://dx.doi.org/10.1002/ jmor.1051380103

Macholán M., Mikulaa O. \& Vohralíkc V. 2008. Geographic phenetic variation of two easternMediterranean non-commensal mouse species, Mus macedonicus and M. cypriacus (Rodentia: Muridae) based on traditional and geometric approaches to morphometrics. Zoologischer Anzeiger 247 (1): 6780. http://dx.doi.org/10.1016/j.jcz.2007.07.003

Mason M.J. 2001. Middle ear structures in fossorial mammals: a comparison with non-fossorial species. Proceedings of the Zoological Society of London 255 (4): 467-86. http://dx.doi.org/10.1017/ $\underline{\mathrm{S} 0952836901001558}$

Mason M.J. 2003. Morphology of the middle ear of golden moles (Chrysochloridae). Proceedings of the Zoological Society of London 260 (4): 391-403. http://dx.doi.org/10.1017/S095283690300387X

Misonne X. 1959. Analyse Zoogéographique des Mammifères de l'Iran. Mémoires de l'Institut royal des Sciences naturelles de Belgique, deuxième série 59, Institut Royal des Sciences Naturelles de Belgique, Brussels.

Misonne X. 1975. The Rodents of the Iranian Deserts. In: Prakash I. \& Ghosh P.K. (eds) Rodents in Desert Environments: 47-58. Monographiae Biologicae 28, Springer Netherlands. http://dx.doi. org/10.1007/978-94-010-1944-6_ 3

Momenzadeh M., Darvish J., Toutoniyan F., Sarmad M. \& Sadeghi Shakib F. 2008. Investigation of climatic effects on the shape and volume of tympanic bulla of Meriones libycus and Meriones persicus (Muridae: Rodentia) from northeastern Iran: an evolutionary approach. Iranian Journal of Animal Biosystematics 4: 63-73.

Monteiro L.R., Duarte L.C. \& Reis S.F. dos 2003. Environmental correlates of geographical variation in skull and mandible shape of Thrichomys apereoides (Rodentia: Echimyidae). Journal of Zoology 261 (1): 47-57. http://dx.doi.org/10.1017/S0952836903003893

Musser G.G. \& Carleton M.D. 2005. Superfamily Muroidea. In: Wilson D.E. \& Reeder D.M. (eds) Mammal Species of the World: A Taxonomic and Geographic Reference (3rd ed.): 894-1531. Johns Hopkins University Press, Baltimore.

Osborn D.J. \& Helmy I. 1980. The Contemporary Land Mammals of Egypt (Including Sinai). Fieldiana Zoology, new series 5, Field Museum of Natural History, Chicago. http://dx.doi.org/10.5962/bhl. $\underline{\text { title. } 2801}$

Pavlinov I.Y. \& Rogovin K.A. 2000. Relation between size of pinna and of auditory bulla in specialized desert rodents. Journal of General Biology 61: 87-101. [In Russian with English summary]

Pavlinov I.Y. 2008. A Review of Phylogeny and Classification of Gerbillinae (Mammalia: Rodentia). Moscow University Publishing, Moscow.

Pavlinov I.Y., Lissovsky A.A. \& Obolenskaya E.V. 2010. Geographic variation of skull traits in the Libyan jird, Meriones libycus (Rodentia: Gerbillinae), over its entire distribution area. Russian Journal of Theriology 9: 19-26.

Petter F. 1959. Evolution du dessin de la surface d'usure des molaires des Gerbillidés. Mammalia 23 (3): 304-315. http://dx.doi.org/10.1515/mamm.1959.23.3.304

Petter F. 1961. Répartition géographique et écologique des rongeurs désertiques (du Sahara occidental à l'Iran oriental). Mammalia 25 (s1): 1-222. 
Popesko P., Rajtová V. \& Horák J. 2002. Colour Atlas of the Anatomy of Small Laboratory Animals. Vol. 2. Rat, Mouse and Golden Hamster. Wolfe Publishing, Bratislava.

Raup D. \& Crick R.E. 1979. Measurement of Faunal Similarity in Paleontology. Journal of Paleontology 53 (5): 1213-1227.

Ranck G. L. 1968. The Rodents of Libya: Taxonomy, Ecology and Zoogeographical Relationships. Bulletin of the United States National Museum 275, Smithsonian Institution Press Washington.

Rohlf F.J. \& Slice D.E. 1990. Extensions of the Procrustes methods for the optimal superimposition of landmarks. Systematic Zoology 39 (1): 40-59. http://dx.doi.org/10.2307/2992207

Rohlf F.J. 1993. Relative Warp Analysis and an Example of its Application to Mosquito Wings. In: Marcus L.F., Bello E. \& Garcia-Valdecasas A. (eds) Contributions to Morphometrics: 131-159. Monografias, Museo Nacional de Ciencias Naturales, Madrid. http://dx.doi.org/10.5962/bhl.title.15368

Rohlf F.J. \& Marcus L.F. 1993. A revolution in Morphometrics. Trends in Ecology \& Evolution 8 (4): 129-132. http://dx.doi.org/10.1016/0169-5347(93)90024-J

Rohlf F.J. 1995. Multivariate Analysis of Shape Using Partial-warp Scores. In: Mardia K.V. \& Leeds C.A. (eds) Proceedings in Current Issues in Statistical Shape Analysis: 154-158. Leeds University Press, Leeds.

Rohlf F.J. 1999. Shape Statistics: Procrustes Superimpositions and Tangent Spaces. Journal of Classification 16 (2): 197-223. http://dx.doi.org/10.1007/s003579900054

Rohlf F.J. \& Corti M. 2000. Use of Two-Block Partial Least Squares to Study Covariation in Shape. Systematic Biology 49 (4): 740-753. http://dx.doi.org/10.1080/106351500750049806

Rohlf F.J. 2003. TpsSmall: Thin Plate Spline Small Variation Analysis, version 1.20. Department of Ecology and Evolution, State University of New York at Stony Brook. Available from http://life.bio. sunysb.edu/morph/ [accessed 20 Jun. 2012]

Rohlf F.J. \& Bookstein F.L. 2003. Computing the Uniform Component of Shape Variation. Systematic Biology 52 (1): 66-69. http://dx.doi.org/10.1080/10635150390132759

Rohlf F.J. 2004a. TpsDig: Thin Plate Spline Digitise, version 2.12. New York: Department of Ecology and Evolution, State University of New York at Stony Brook.. Available from http://life.bio.sunysb.edu/

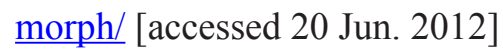

Rohlf F.J. 2004b. TpsSplin: Thin Plate Spline, version 1.20. Department of Ecology and Evolution, State University of New York at Stony Brook. Available from http://life.bio.sunysb.edu/morph/ [accessed 20 Jun. 2012]

Rohlf F.J. 2008. TpsRelw: Thin Plate Spline Relative Warps, version 1.46. Departement of Ecology and Evolution, State University of New York at Stony Brook. Available from http://life.bio.sunysb.edu/

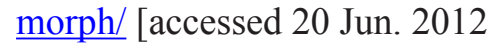

Schleich C.E. \& Vasallo A.I. 2003. Bullar Volume in Subterranean and Surface-Dwelling Caviomorph Rodents. Journal of Mammalogy 84 (1): 185-189. http://dx.doi.org/10.1644/15451542(2003)084<0185:BVISAS >2.0.CO;2

Sénégas F. 2001. Interpretation of the dental pattern of the South African fossil Euryotomys (Rodentia, Murinae), and origin of otomyine dental morphology). In: Denys C., Granjon L. \& Poulet A. (eds) African Small Mammals. Proceedings of the 8th International Symposium on African Small Mammals: 151-160. Colloques et Séminaires, Institut de recherche pour le développement, Paris. 
StatSoft, Inc. 2004. STATISTICA (data analysis software system), version 7. Available from www. statsoft.com [accessed 20 Jun. 2012]

Tabatabaei Yazdi F. \& Adriaens D. 2011. Patterns of phenotypic skull variation in M. persicus (Rodentia: Muridae) in relation to geoclimatic conditions. Iranian Journal of Animal Biosystematics 7 (2): 129-142.

Tabatabaei Yazdi F., Adriaens D. \& Darvish J. 2012. Geographic pattern of cranial differentiation in the Asian Midday Jird Meriones meridianus (Rodentia: Muridae: Gerbillinae) and its taxonomic implications. Journal of Zoological Systematics and Evolutionary Research 50 (2): 157-164. http:// dx.doi.org/10.1111/j.1439-0469.2011.00642.x

Thomas O. 1919. Notes on Gerbils referred to the Genus Meriones, with Descriptions of new Species and Subspecies. The Annals and Magazine of Natural History 3: 263-273. http://dx.doi. org/10.1080/00222931908673822

Tong H. 1989. Origine et évolution des Gerbillidae (Mammalia, Rodentia) en Afrique Du Nord. Mémoires de la Société géologique de France, nouvelle série 155, Société géologique de France, Paris.

Vaughan T.A., Ryan J.M. \& Czaplewski N.J. 2000. Mammalogy (4th ed.). Saunders College Publishers, Orlando, Florida.

Van der Straeten E. \& Dieterlen F. 1992. Craniometrical comparison of four populations of Praomys jacksoni captured at different heights in Eastern Zaire (Kivu). Mammalia 56 (1): 125-31.

Webster D.B. \& Webster M. 1984. The Specialized Auditory System of Kangaroo Rats. Contributions to Sensory Physiology 8: 161-196. http://dx.doi.org/10.1016/B978-0-12-151808-0.50012-5

Webster D.B. \& Plassmann W. 1992. Parallel Evolution of Low-Frequency Sensitivity in Old World and New World Desert Rodents. In: Webster D.B., Popper A.N. \& Fay R.R. (eds) The Evolutionary Biology of Hearing: 625-631. Springer-Verlag, New York. http://dx.doi.org/10.1007/978-1-4612-2784-7_39

Wittmer W. \& Büttiker W. 1982. Fauna of Saudi Arabia. Vol. 4. Pro Entomologia, c/o Natural History Museum, California.

Zelditch M.L., Swiderski D.L., Sheets H.D. \& Fink W.L. 2004. Geometric Morphometrics for Biologists: a Primer. Elsevier Academic Press, London.

Manuscript received: 11 August 2013

Manuscript accepted: 1 April 2014

Published on: 25 June 2014

Topic editor: Rudy Jocqué

Desk editor: Charlotte Thionois

Printed versions of all papers are also deposited in the libraries of the institutes that are members of the EJT consortium: Muséum National d'Histoire Naturelle, Paris, France; Botanic Garden Meise, Belgium; Royal Museum for Central Africa, Tervuren, Belgium; Natural History Museum, London, United Kingdom; Royal Belgian Institute of Natural Sciences, Brussels, Belgium; Natural History Museum of Denmark, Copenhagen, Denmark. 
TABATABAEI YAZDI F., ADRIAENS D. \& DARVISH J., Morphological variation in jirds

Appendix 1. Catalogue numbers of the analysed specimens.

\section{Meriones crassus}

Smithsonian National Museum of Natural History (Washington D.C., USA)

328235, 328236, 350507, 350508, 350509, 350479, 350481, 329156, 329157, 350468, 350470, 350471, 350472, 350475, 350476, 350477, 350478, 354739, 354741, 354743, 369465, 369466, 350500, 350501, 350503, 350505, 326904, 326905, 326906, 326910, 326911, 326914, 326915, 326916, 326918, 326919, 326920, 326921, 326922, 326923, 326924, 326926, 326928, 326931, 326932, 326935, 326937, 326940, 326947,328228 , 328230, 328231, 328232, 328233, 328245, 328246, 328248, 354732, 354733, 354734, 354735 , 354736, 350484, 350487, 350488, 350489, 350490, 350491, 350492, 350493, 350494, 350196, $350497,350498,350512,354710,354711,354712$, 354713, 354714, 354715, 3564716, 354717, $354718,354719,354721,354722$, 354723, 354724, 354727, 354729, 354699, 354701, 354702, 354703, $354704,354705,354706,354707,354708,354709$, 328237, 328238, 328239, 328240, 328243, 329151, 329153, 329154, 329155, 354738, 369467, 369468, 369470, 369471, 369472, 369473, 369474, 369476, 369486, 369489, 369490, 369491, 369492, 369493, 369505, 369506, 369507, 322693, 322659, 322660, 322661,322662 , 322663, 322664, 322665, 322666, 322667, 322668, 322694, 322695, 282504, 282505, 282506, 282507, 282508, 282509, 282512, 282513, 283230, 283231, 321872, 321873, 321874, 401157, 401158, 401159, 401160, 401161, 401162, 401163, 401165, 401166, 401167, 401168, 401169, 401171, 401172, 401173, 401174, 401175, 401176, 401177, 401178, 401179, 401180, 401181.

\section{Field Museum of Natural History (Chicago, USA)}

103308, 103311, 103312, 103313, 103314, 103315, 103317, 103318, 103319, 103321, 103322, 103323, 97234, 97238, 97227, 97231, 97232, 97249, 97214, 97216, 97220, 97221, 97223, 97248, 111954, $111655,153162,153161,179005,179008,87612,87618$.

\section{British Museum of Natural History (London, UK)}

19.7.7.2356, 19.7.7.2808, 47.508, 47.514, 47.510, 47.518, 47.509, 47.513, 95.350, 47.523, 47.529, $66.2584,471537,471535,471538,1979.2052,1968.949,1968.947,1968948,206814,1957.10,206813$, 846146, 1023243, 51311, 196124, 196125, 54247, 23241.

Muséum national d'Histoire naturelle (Paris, France)

1997-403, 1957-1340, 1955-21, 1957-519, 1953-4230, 1957-1036, 1957-1039, 1957-1043, 1953-425, 1958-104, 1957-1042, 1957-1037, 1957-1038, 1991-1220, 1952-532, 1957-329, 1957-325, 1957-314, 1958-63, 1957-321, 1957-528, 1957-316, 1958-61, 1958-62, 1957-825, 1957-318, 1957-328, 1957-330, 1966-1054, 1957-823, 1957-311, 1957-315, 1957-309, 1957-307, 1957-312, 1957-320, 1958-6423, 1957-306, 1957-326, 1957-323, 1958-65, 1957-322, 1958-107, 1958-106, 1957-1354, 1995-1700.

\section{Meriones libycus}

Smithsonian National Museum of Natural History (Washington D.C., USA)

326941, 326942, 326943, 326944, 326969, 326970, 326971, 326973, 328266, 328267, 328269, 369798, 369799, 369801, 369802, 369806, 369808, 369810, 369812, 369814, 369815, 369817, 369818, 369819, 369822, 369824, 369826, 369827, 369828, 369829, 369831, 369832, 369833, 369834, 354682, 326968, $328257,328258,328260,328262$, 328264, 328265, 354690, 354691, 354692, 354695, 341256, 341258, 341261,341262 , 341263, 341264, 341265, 341266, 341267, 328224, 328225, 328271, 328272, 328273, $328274,328275,329188,329189,329190,329191,354696,354661,350558,350559,350572,354647$, $354649,354650,354652,354653,354664,354665$.

\section{British Museum of Natural History (London, UK)}

$40.259,1983.314,40.257,25.4 .3 .43,25.4 .3 .23,10.3 .12 .4,25.4 .3 .25,5.7 .2 .3,25.4 .3 .20,47.383$, 56.2.29.5, 19.12.10.3, 47.1412, 47.1414. 


\section{Zoological Museum of Ferdowsi University of Mashhad (Mashhad, Iran)}

M564, M799, M810, M785, 322, 245, M-35, 1021, 30, 1499, 909, 1473, 1504, 303, 208, 474, 1470, 1468, M844, M571, 1506, 1471, 217, M-17, M-35, 157, M-3, 39, M-28, M-36, 205, 212, M-21, 174, M-29, 1469, 24, M-34, M-7, 518, M-37, 176, 563, M-1, 1482, 574, 461, 88, 9, M-572, M-579, M-12, M-808, 4, M-432, M343, 2, M-331, M-188, M-646, M-196, M-11, 850, 11, M-111, M-842, M-573, 7, M-175, M-548, 14, M-694, M-568, M-236, M-251, 840, 577, 106, M-3, M-12.

\section{Muséum national d'Histoire naturelle (Paris, France)}

1950-468, 1950-508, 1957-1330, 1957-1338, 1957-1339, 1958-89, 1958-91, 1958-330, 1958-331, 1958-336, 1958-341, 1958342, 1958343, 1958-344, 1958-345, 1958-346, 1958-347, 1958-351, 1958 $352,1958-750,1957-334,1957-335,1957-332,1957-336$.

\section{Royal Belgian Institute of Natural Sciences (Brussels, Belgium)}

10186, 10190, 10189, 10187, 10348, 10322, 10192, 10078, 10137, 10283, 10184, 10497, 10185, 10188, 10318, 10319, 10082, 10282, 10194. 
TABATABAEI YAZDI F., ADRIAENS D. \& DARVISH J., Morphological variation in jirds

Appendix 2. Overview of sampling localities of Meriones crassus Sundevall, 1842 (M. c.) and M. libycus Lichtenstein, 1823 (M. l.) used in this study. $\mathrm{F}=$ female; $\mathrm{M}=$ male. Total = both sexes including specimens of unknown sex.

\begin{tabular}{|c|c|c|c|c|c|c|c|}
\hline \multirow{2}{*}{ Taxon } & \multirow{2}{*}{ Country } & \multirow{2}{*}{ Locality } & \multirow{2}{*}{ Latitude } & \multirow{2}{*}{ Longitude } & \multicolumn{3}{|c|}{ Sample size } \\
\hline & & & & & $\mathbf{F}$ & $\mathbf{M}$ & Total \\
\hline M. $c$. & Iran & Abas abad & $36.38^{\circ} \mathrm{N}$ & $53.05^{\circ} \mathrm{E}$ & 7 & 9 & 16 \\
\hline M. $c$. & Iran & Esfahan & $33.22^{\circ} \mathrm{N}$ & $51.68^{\circ} \mathrm{E}$ & 2 & 1 & 3 \\
\hline M. c. & Iran & Kashan & $33.98^{\circ} \mathrm{N}$ & $51.45^{\circ} \mathrm{E}$ & 0 & 2 & 2 \\
\hline M. c. & Iran & Kerman & $30.28^{\circ} \mathrm{N}$ & $57.10^{\circ} \mathrm{E}$ & 8 & 9 & 17 \\
\hline M. c. & Iran & Khash, Iranshahr & $28.22^{\circ} \mathrm{N}$ & $61.20^{\circ} \mathrm{E}$ & 2 & 2 & 4 \\
\hline M. c. & Iran & Kashmar & $35.17^{\circ} \mathrm{N}$ & $57.42^{\circ} \mathrm{E}$ & 5 & 11 & 16 \\
\hline M. $c$. & Iran & Dasht-e- Lut & $32.58^{\circ} \mathrm{N}$ & $59.03^{\circ} \mathrm{E}$ & 1 & 1 & 2 \\
\hline M. c. & Iran & Mashad & $36.05^{\circ} \mathrm{N}$ & $58.85^{\circ} \mathrm{E}$ & 4 & 1 & 5 \\
\hline M. c. & Iran & Qazvin & $36.81^{\circ} \mathrm{N}$ & $51.05^{\circ} \mathrm{E}$ & 1 & 1 & 2 \\
\hline M. c. & Iran & Sabzevar & $36.25^{\circ} \mathrm{N}$ & $57.75^{\circ} \mathrm{E}$ & 2 & 3 & 5 \\
\hline M. c. & Iran & Shahrud & $36.42^{\circ} \mathrm{N}$ & $54.96^{\circ} \mathrm{E}$ & 4 & 6 & 10 \\
\hline M. $c$. & Iran & Torbat-e-heidariyeh & $35.36^{\circ} \mathrm{N}$ & $59.22^{\circ} \mathrm{E}$ & 9 & 7 & 16 \\
\hline M. $c$. & Iran & Zahedan & $29.21^{\circ} \mathrm{N}$ & $60.87^{\circ} \mathrm{E}$ & 2 & 5 & 7 \\
\hline M. $c$. & Iran & Mahallat & $33.75^{\circ} \mathrm{N}$ & $50.50^{\circ} \mathrm{E}$ & 1 & 1 & 2 \\
\hline M. c. & Iran & Tazuki & $30.40^{\circ} \mathrm{N}$ & $61.14^{\circ} \mathrm{E}$ & 1 & 0 & 1 \\
\hline M. c. & Iran & Andimeshk & $33.20^{\circ} \mathrm{N}$ & $48.25^{\circ} \mathrm{E}$ & 3 & 11 & 14 \\
\hline M. c. & Iran & Ahvaz & $31.18^{\circ} \mathrm{N}$ & $49.60^{\circ} \mathrm{E}$ & 1 & 2 & 3 \\
\hline M. c. & Iran & Qhasr-e-shirin & $34.51^{\circ} \mathrm{N}$ & $45.58^{\circ} \mathrm{E}$ & 4 & 4 & 8 \\
\hline M. $c$. & Iran & Taj maleki & $29.76^{\circ} \mathrm{N}$ & $50.56^{\circ} \mathrm{E}$ & 2 & 0 & 2 \\
\hline M. c. & Afghanistan & Qala Bist & $31.33^{\circ} \mathrm{N}$ & $64.20^{\circ} \mathrm{E}$ & 3 & 9 & 12 \\
\hline M. c. & Pakistan & Baluchistan & $28.58^{\circ} \mathrm{N}$ & $65.41^{\circ} \mathrm{E}$ & 1 & 4 & 5 \\
\hline M. c. & Pakistan & Nok kundi & $28.81^{\circ} \mathrm{N}$ & $62.77^{\circ} \mathrm{E}$ & 5 & 3 & 8 \\
\hline M. c. & Pakistan & Panjgur & $26.75^{\circ} \mathrm{N}$ & $64.00^{\circ} \mathrm{E}$ & 1 & 3 & 4 \\
\hline M. c. & Iraq & Kirkuk & $35.47^{\circ} \mathrm{N}$ & $44.13^{\circ} \mathrm{E}$ & 5 & 3 & 8 \\
\hline M. c. & Iraq & Ali al Gharbi & $32.46^{\circ} \mathrm{N}$ & $46.68^{\circ} \mathrm{E}$ & 6 & 7 & 13 \\
\hline M. c. & Kuwait & Al ahmadi & $29.07^{\circ} \mathrm{N}$ & $48.08^{\circ} \mathrm{E}$ & 4 & 6 & 13 \\
\hline M. $c$. & Saudi Arabia & Qariya, Hafar-al-Batin & $27.20^{\circ} \mathrm{N}$ & $44.00^{\circ} \mathrm{E}$ & 4 & 6 & 10 \\
\hline M. c. & Saudi Arabia & Jeddah & $21.51^{\circ} \mathrm{N}$ & $39.22^{\circ} \mathrm{E}$ & 0 & 1 & 2 \\
\hline M. c. & Israel & Ein Hussub & $31.78^{\circ} \mathrm{N}$ & $35.22^{\circ} \mathrm{E}$ & 1 & 2 & 3 \\
\hline M. c. & Jordan & Zarqa,Ma'am & $31.59^{\circ} \mathrm{N}$ & $37.24^{\circ} \mathrm{E}$ & 2 & 0 & 2 \\
\hline M. c. & Egypt & Al Qahriah & $30.10^{\circ} \mathrm{N}$ & $31.33^{\circ} \mathrm{E}$ & 8 & 4 & 12 \\
\hline M. c. & Libya & Awbari, El Gatrun & $29.06^{\circ} \mathrm{N}$ & $15.78^{\circ} \mathrm{E}$ & 8 & 5 & 13 \\
\hline M. c. & Mauritania & Fort Gouraud & $22.61^{\circ} \mathrm{N}$ & $-12.73^{\circ} \mathrm{W}$ & 15 & 8 & 23 \\
\hline M. c. & Western Sahara & Aguera & $20.83^{\circ} \mathrm{N}$ & $-17.09^{\circ} \mathrm{W}$ & 1 & 0 & 1 \\
\hline M. $l$. & Iran & Geno & $27.41^{\circ} \mathrm{N}$ & $56.18^{\circ} \mathrm{E}$ & 0 & 0 & 1 \\
\hline M. $l$. & Iran & Jajarm & $36.93^{\circ} \mathrm{N}$ & $56.36^{\circ} \mathrm{E}$ & 0 & 0 & 1 \\
\hline M. $l$. & Iran & Kashmar & $35.18^{\circ} \mathrm{N}$ & $57.41^{\circ} \mathrm{E}$ & 0 & 0 & 1 \\
\hline M. $l$. & Iran & Sabzevar & $29.60^{\circ} \mathrm{N}$ & $52.51^{\circ} \mathrm{E}$ & 0 & 0 & 1 \\
\hline M. $l$. & Iran & Bajestan & $34.51^{\circ} \mathrm{N}$ & $58.18^{\circ} \mathrm{E}$ & 0 & 1 & 2 \\
\hline
\end{tabular}




\begin{tabular}{|c|c|c|c|c|c|c|c|}
\hline \multirow{2}{*}{ Taxon } & \multirow{2}{*}{ Country } & \multirow{2}{*}{ Locality } & \multirow{2}{*}{ Latitude } & \multirow{2}{*}{ Longitude } & \multicolumn{3}{|c|}{ Sample size } \\
\hline & & & & & $\mathbf{F}$ & M & Total \\
\hline M. $l$. & Iran & Kouhak, Zabol & $31.06^{\circ} \mathrm{N}$ & $61.75^{\circ} \mathrm{E}$ & 2 & 0 & 2 \\
\hline M. $l$. & Iran & Garmsar & $35.13^{\circ} \mathrm{N}$ & $52.18^{\circ} \mathrm{E}$ & 0 & 0 & 3 \\
\hline M. $l$. & Iran & Kerman & $29.90^{\circ} \mathrm{N}$ & $56.53^{\circ} \mathrm{E}$ & 0 & 0 & 3 \\
\hline M. $l$. & Iran & Gonbad-e-Kavus & $37.23^{\circ} \mathrm{N}$ & $55.08^{\circ} \mathrm{E}$ & 2 & 3 & 6 \\
\hline M. $l$. & Iran & Shirvan & $37.45^{\circ} \mathrm{N}$ & $57.91^{\circ} \mathrm{E}$ & 0 & 3 & 4 \\
\hline M. $l$. & Iran & Torbat-e-Heidariyeh & $35.28^{\circ} \mathrm{N}$ & $59.21^{\circ} \mathrm{E}$ & 0 & 1 & 4 \\
\hline M. $l$. & Iran & Zahedan & $29.53^{\circ} \mathrm{N}$ & $60.83^{\circ} \mathrm{E}$ & 3 & 2 & 5 \\
\hline M. $l$. & Iran & Torbat-e-Jam & $35.21^{\circ} \mathrm{N}$ & $60.61^{\circ} \mathrm{E}$ & 0 & 1 & 8 \\
\hline M. $l$. & Iran & Nehbandan & $31.53^{\circ} \mathrm{N}$ & $60.03^{\circ} \mathrm{E}$ & 1 & 4 & 8 \\
\hline M. $l$. & Iran & Ghoochan & $37.10^{\circ} \mathrm{N}$ & $58.50^{\circ} \mathrm{E}$ & 3 & 5 & 8 \\
\hline M. $l$. & Iran & Sabzevar & $36.20^{\circ} \mathrm{N}$ & $57.71^{\circ} \mathrm{E}$ & 3 & 4 & 8 \\
\hline M. $l$. & Iran & Khash & $35.18^{\circ} \mathrm{N}$ & $58.45^{\circ} \mathrm{E}$ & 2 & 6 & 9 \\
\hline M. $l$. & Iran & Mashhad & $36.26^{\circ} \mathrm{N}$ & $59.61^{\circ} \mathrm{E}$ & 1 & 3 & 10 \\
\hline M. $l$. & Iran & Sarakhs & $36.50^{\circ} \mathrm{N}$ & $61.05^{\circ} \mathrm{E}$ & 0 & 5 & 9 \\
\hline M. $l$. & Iran & Bojnurd & $37.46^{\circ} \mathrm{N}$ & $57.31^{\circ} \mathrm{E}$ & 8 & 7 & 15 \\
\hline M. $l$. & Iran & Dashli Borun & $37.63^{\circ} \mathrm{N}$ & $54.81^{\circ} \mathrm{E}$ & 10 & 7 & 17 \\
\hline M. $l$. & Iran & Birjand & $32.86^{\circ} \mathrm{N}$ & $59.20^{\circ} \mathrm{E}$ & 5 & 9 & 22 \\
\hline M. $l$. & Iran & Mansourabad & $28.25^{\circ} \mathrm{N}$ & $54.03^{\circ} \mathrm{E}$ & 12 & 11 & 23 \\
\hline M. $l$. & Iran & Robat e-Gharabil & $37.35^{\circ} \mathrm{N}$ & $56.31^{\circ} \mathrm{E}$ & 1 & 2 & 3 \\
\hline M. $l$. & Iran & Qazvin & $36.26^{\circ} \mathrm{N}$ & $50.01^{\circ} \mathrm{E}$ & 0 & 0 & 8 \\
\hline M. $l$. & Iran & Aghbulagh & $35.61^{\circ} \mathrm{N}$ & $48.43^{\circ} \mathrm{E}$ & 2 & 2 & 4 \\
\hline M. $l$. & Iran & Tehran & $35.85^{\circ} \mathrm{N}$ & $50.86^{\circ} \mathrm{E}$ & 0 & 0 & 1 \\
\hline M. $l$. & Iran & Hamedan & $35.70^{\circ} \mathrm{N}$ & $48.20^{\circ} \mathrm{E}$ & 0 & 2 & 3 \\
\hline M. $l$. & Iran & Ahvaz & $31.18^{\circ} \mathrm{N}$ & $49.60^{\circ} \mathrm{E}$ & 0 & 3 & 3 \\
\hline M. $l$. & Afghanistan & Kandahar & $31.60^{\circ} \mathrm{N}$ & $65.70^{\circ} \mathrm{E}$ & 0 & 1 & 2 \\
\hline M. $l$. & Iraq & Ali al Gharbi & $32.46^{\circ} \mathrm{N}$ & $46.67^{\circ} \mathrm{E}$ & 1 & 3 & 4 \\
\hline M. $l$. & Saudi Arabia & Hufuf & $25.37^{\circ} \mathrm{N}$ & $49.58^{\circ} \mathrm{E}$ & 0 & 2 & 2 \\
\hline M. $l$. & Saudi Arabia & Shari wells, NW Arabia & $24.49^{\circ} \mathrm{N}$ & $44.38^{\circ} \mathrm{E}$ & 6 & 1 & 8 \\
\hline M. $l$. & Syria & Al Qaryatayn & $34.23^{\circ} \mathrm{N}$ & $37.23^{\circ} \mathrm{E}$ & 0 & 2 & 2 \\
\hline
\end{tabular}


TABATABAEI YAZDI F., ADRIAENS D. \& DARVISH J., Morphological variation in jirds

Appendix 3. Definition and numbering of the landmarks used for the skull morph analyses.

\begin{tabular}{|c|c|}
\hline Landmark & Definition \\
\hline \multicolumn{2}{|l|}{ Ventral view } \\
\hline 1 & rostral tip of internasal suture \\
\hline 2 & most lateral junction point of incisive alveolus and body of premaxillary bone \\
\hline 3 & most rostral point of incisive foramen \\
\hline 4 & most caudal point of incisive foramen \\
\hline 5 & most rostral point of palatine foramen \\
\hline 6 & most caudal point of palatine foramen \\
\hline 7 & most rostral point on the alveolus of the first molar \\
\hline 8 & most caudal point on the alveolus of the third molar \\
\hline 9 & most caudal point of median suture of palatine bone \\
\hline 10 & most rostral point of foramen magnum \\
\hline 11 & most lateral point of occipital condyle \\
\hline 12 & most caudal point of acoustic tympanic bulla \\
\hline 13 & rostral curvature point at level of the meatus \\
\hline 14 & most caudal point of zygomatic process concavity formed by temporal bone \\
\hline 15 & intersection between frontal squama, wing of presphenoid bone and wing of basisphenoid bone \\
\hline 16 & most lateral point of zygomatic arch at maximum width of skull \\
\hline 17 & rostral point of zygomatic plate \\
\hline 18 & maximum curvature of zygomatic plate in infraorbital foramen \\
\hline 19 & intersection of zygomatic arch and vertical line passing through most caudal point of third molar \\
\hline 20 & intersection of the zygomatic plate and line connecting landmarks 13 and 18 \\
\hline \multicolumn{2}{|l|}{ Dorsal view } \\
\hline 1 & rostral tip of internasal suture \\
\hline 2 & intersection of naso-frontal suture with the internasal suture \\
\hline 3 & intersection of frontal-parietal suture and the interparietal suture \\
\hline 4 & intersection of suture between left and right parietals, and parietal-interparietal suture \\
\hline 5 & midline point of suture between interparietal and occipital \\
\hline 6 & midline point of caudal margin of the occipital \\
\hline 7 & most rostral point of suture between nasal and premaxilla \\
\hline 8 & rostral end of zygomatic plate \\
\hline 9 & most lateral point of zygomatic plate \\
\hline 10 & lateral end of the maxillary-frontal suture \\
\hline 11 & rostral point of upper orbital crest at level of interorbital depression \\
\hline 12 & intersection of temporal line and suture between parietal and squamosal bones \\
\hline 13 & tip of concavity of squamosal root of zygomatic arch \\
\hline 14 & caudal tip of squamosal root of zygomatic arch \\
\hline 15 & rostrolateral end of tympanic bulla convexity \\
\hline 16 & caudal end of tympanic bulla on lateral edge of suprameatal process (supramastoid part of squamosal bone) \\
\hline 17 & distal tip of lateral process of supraoccipital \\
\hline 18 & caudal end of suture between the mastoid part of tympanic bulla and supraoccipital \\
\hline 19 & intersection of parietal-interparietal and interparietal-occipital sutures \\
\hline
\end{tabular}




\begin{tabular}{|c|c|}
\hline Lateral view & \\
\hline 1 & most rostral point of nasal \\
\hline 2 & inner extreme point of incisor at body of premaxillary bone \\
\hline 3 & point at intersection between premaxillary and posterior end of incisive alveolus \\
\hline 4 & most rostral end of infraorbital foramen edge on zygomatic plate \\
\hline 5 & most ventral point at the margin of zygomatic plate \\
\hline 6 & most caudal point of infraorbital foramen on zygomatic plate \\
\hline 7 & most rostral point of suture between lacrimal and zygomatic plate \\
\hline 8 & most rostral point of molar on alveolar process of maxilla \\
\hline 9 & most caudal point of molar on alveolar process of maxilla \\
\hline 10 & most caudal point of optic canal \\
\hline 11 & middle of alisphenoid canal \\
\hline 12 & most caudal point of suture between jugal and squamosal root of zygomatic arch \\
\hline 13 & $\begin{array}{l}\text { intersection between rostral edge of tympanic bulla and most caudal point of gap between tympanic bulla } \\
\text { and occipital process of temporal bone }\end{array}$ \\
\hline 14 & rostral point of suprameatal triangle \\
\hline 15 & lateral tip of supraoccipital process \\
\hline 16 & tip of hamular process of temporal on suprameatal triangle \\
\hline 17 & rostral end of suture between stylomastoid suture and stylomastoid foramen \\
\hline 18 & most rostral point of paraoccipital process \\
\hline 19 & intersection of suture between parietal and supraoccipital with suprameatal process of squamosa \\
\hline 20 & intersection of temporal line and suture between parietal and squamosal \\
\hline 21 & $\begin{array}{l}\text { junction of suture between parietal and squamosal bone and suture between frontal and squamosal part of } \\
\text { temporal bone }\end{array}$ \\
\hline 22 & intersection of tympanic part of bulla and line connecting landmarks 16 and 17 \\
\hline
\end{tabular}

